\title{
Atmospheric methane and carbon dioxide from SCIAMACHY satellite data: initial comparison with chemistry and transport models
}

\author{
M. Buchwitz ${ }^{1}$, R. de Beek ${ }^{1}$, J. P. Burrows ${ }^{1}$, H. Bovensmann ${ }^{1}$, T. Warneke ${ }^{1}$, J. Notholt ${ }^{1}$, J. F. Meirink ${ }^{2}$, A. P. H. Goede ${ }^{2}$, \\ P. Bergamaschi ${ }^{3}$, S. Körner ${ }^{4}$, M. Heimann ${ }^{4}$, and A. Schulz ${ }^{5}$ \\ ${ }^{1}$ Institute of Environmental Physics (IUP), University of Bremen FB1, Bremen, Germany \\ ${ }^{2}$ Royal Netherlands Meteorological Institute (KNMI), Utrecht, The Netherlands \\ ${ }^{3}$ Institute for Environment and Sustainability, Joint Research Centre (EC-JRC-IES), Ispra, Italy \\ ${ }^{4}$ Max Planck Institute for Biogeochemistry (MPI-BGC), Jena, Germany \\ ${ }^{5}$ Alfred Wegener Institute (AWI), Potsdam, Germany
}

Received: 5 July 2004 - Published in Atmos. Chem. Phys. Discuss.: 5 November 2004

Revised: 9 February 2005 - Accepted: 11 March 2005 - Published: 21 March 2005

\begin{abstract}
The remote sensing of the atmospheric greenhouse gases methane $\left(\mathrm{CH}_{4}\right)$ and carbon dioxide $\left(\mathrm{CO}_{2}\right)$ in the troposphere from instrumentation aboard satellites is a new area of research. In this manuscript, results obtained from observations of the up-welling radiation in the near-infrared by SCIAMACHY on board ENVISAT are presented. Vertical columns of $\mathrm{CH}_{4}, \mathrm{CO}_{2}$ and oxygen $\left(\mathrm{O}_{2}\right)$ have been retrieved and the (air or) $\mathrm{O}_{2}$-normalised $\mathrm{CH}_{4}$ and $\mathrm{CO}_{2}$ column amounts, the dry air column averaged mixing ratios $\mathrm{XCH}_{4}$ and $\mathrm{XCO}_{2}$ derived. In this manuscript the first results, obtained by using the version 0.4 of the Weighting Function Modified (WFM) DOAS retrieval algorithm applied to SCIAMACHY data, are described and compared with global models. For the set of individual cloud free measurements over land the standard deviation of the difference with respect to the models is in the range $\sim 100-200 \mathrm{ppbv}(5-10 \%)$ for $\mathrm{XCH}_{4}$ and $\sim 14-32 \mathrm{ppmv}$ (4-9\%) for $\mathrm{XCO}_{2}$. The interhemispheric difference of the methane mixing ratio, as determined from single day data, is in the range $30-110 \mathrm{ppbv}$ and in reasonable agreement with the corresponding model data (48-71 ppbv). The weak inter-hemispheric difference of the $\mathrm{CO}_{2}$ mixing ratio can also be detected with single day data. The spatiotemporal pattern of the measured and the modelled $\mathrm{XCO}_{2}$ are in reasonable agreement. However, the amplitude of the difference between the maximum and the minimum for SCIAMACHY $\mathrm{XCO}_{2}$ is about $\pm 20 \mathrm{ppmv}$ which is about a factor of four larger than the variability of the model data which is about \pm 5 ppmv. More studies are needed to explain the observed differences. The $\mathrm{XCO}_{2}$ model field shows low $\mathrm{CO}_{2}$ concentrations beginning of January 2003 over a spatially extended $\mathrm{CO}_{2}$ sink region located
\end{abstract}

Correspondence to: M. Buchwitz

(michael.buchwitz@iup.physik.uni-bremen.de) in southern tropical/sub-tropical Africa. The SCIAMACHY data also show low $\mathrm{CO}_{2}$ mixing ratios over this area. According to the model the sink region becomes a source region about six months later and exhibits higher mixing ratios. The SCIAMACHY and the model data over this region show a similar time dependence over the period from January to October 2003. These results indicate that for the first time a regional $\mathrm{CO}_{2}$ surface source/sink region has been detected by measurements from space. The interpretation of the SCIAMACHY $\mathrm{CO}_{2}$ and $\mathrm{CH}_{4}$ measurements is difficult, e.g., because the error analysis of the currently implemented retrieval algorithm indicates that the retrieval errors are on the same order as the small greenhouse gas mixing ratio changes that are to be detected.

\section{Introduction}

A prerequisite for reliable predictions of future atmospheric greenhouse gas amounts is an adequate understanding of the temporal and spatial behaviour of the surface sources and sinks and their response to climate change. Our understanding of the spatial distribution and temporal evolution of atmospheric methane and carbon dioxide is limited by our current knowledge of their sources and sinks: their variability being a significant source of uncertainty (see, e.g. Houweling et al., 1999; Gurney et al., 2002, and references given therein). Our knowledge about the spatial and temporal pattern of sources and sinks of $\mathrm{CH}_{4}$ and $\mathrm{CO}_{2}$ stems in large part from the inverse modelling of the in-situ measurements of a highly accurate but rather sparse network of surface stations (e.g. NOAA/CMDL). The results, obtained at scales of continents and oceanic basins, yield annual source/sink strengths

(C) 2005 Author(s). This work is licensed under a Creative Commons License. 
with significant uncertainty (on the order of $100 \%$ for many regions) (Houweling et al., 1999; Gurney et al., 2002).

Retrievals of the amounts and distributions from spaced based remote sensing instrumentation have the potential to overcome the limitations of the surface network. This, however, requires high accuracy and precision. Rayner and O'Brian (2001) conclude that for $\mathrm{CO}_{2}$ a precision of $2.5 \mathrm{ppmv}(\sim 0.7 \%)$ for monthly averaged column data at $8 \times 10^{\circ}$ spatial resolution is needed for a performance comparable to the current network of ground stations. Similar conclusions have been drawn by other studies, e.g. Houweling et al. (2003), where characteristics of the SCIAMACHY instrument (e.g., spatial sampling) are taken into account in estimating regional $\mathrm{CO}_{2}$ source/sink uncertainty reductions. For methane such detailed studies are currently not available but similar requirements are to be expected.

Measuring $\mathrm{CH}_{4}$ and $\mathrm{CO}_{2}$ from space is a new research area and only a few relevant studies exist. Chedin et al. (2003) reported recently on their retrieval of mid-tropospheric $\mathrm{CO}_{2}$ concentrations in the tropical region $\left(20^{\circ} \mathrm{N}-20^{\circ} \mathrm{S}\right)$ derived from TOVS/NOAA-10 observations.

The first global maps of $\mathrm{CH}_{4}$ columns have been retrieved from IMG/ADEOS thermal infrared (TIR) nadir spectra (Kobayashi et al., 1999a,b; Clerbaux et al., 2003). The results show qualitatively the expected variability, for example the North-South hemispheric gradient but also have some limitations, related to the retrieval algorithm (Clerbaux et al., 2003). TIR nadir $\mathrm{CH}_{4}$ and $\mathrm{CO}_{2}$ observations have their maximum sensitivity in the middle troposphere and are relatively insensitive to the lower troposphere, due to the lack of thermal contrast. However many of the sources and sinks of $\mathrm{CH}_{4}$ and $\mathrm{CO}_{2}$ are located in the boundary layer, thus the modulation of the mixing ratios of these gases resulting from regional sources and sinks is most significant in the boundary layer. The SCIAMACHY near-infrared (NIR) nadir measurements are highly sensitive to concentration changes at all altitude levels, including the boundary layer. As absorption is measured, the measurements are sensitive to the column in a given altitude range rather than the mixing ratio. This is also true for the near-infrared $\mathrm{CH}_{4}$ measurements of the MOPITT instrument on-board EOS-Terra, which utilises gas correlation spectroscopy, but the $\mathrm{CH}_{4}$ column data product of MOPITT has not yet been released (http://terra.nasa.gov/About/MOPITT/).

Vertical columns of atmospheric $\mathrm{CH}_{4}$ and $\mathrm{CO}_{2}$ are retrieved from nadir spectra of the up-welling radiance in the near-infrared spectral region, measured by the SCIAMACHY instrument. $\mathrm{CH}_{4}$ and $\mathrm{CO}_{2}$ have been retrieved respectively from the spectral regions $2265-2280$ and 1558$1594 \mathrm{~nm}$, which are relatively free from interfering absorber. Simultaneously, oxygen $\left(\mathrm{O}_{2}\right)$ columns have been retrieved from the oxygen A band (around $760 \mathrm{~nm}$ ). This enables the dry air column averaged mixing ratios, denoted as $\mathrm{XCH}_{4}$ and $\mathrm{XCO}_{2}$, to be determined: $\mathrm{XCH}_{4}:=\mathrm{CH}_{4}$-column $/ \mathrm{O}_{2}-$ column $\times 0.2095$, where 0.2095 is the $\mathrm{O}_{2}$ mixing ratio of dry air $\left(\mathrm{XCO}_{2}\right.$ is defined analogously).

A subset of the SCIAMACHY data products discussed in this paper has been compared with Fourier Transform Spectroscopy (FTS) solar occultation measurements obtained during a cruise of the German research vessel Polarstern from Cape Town to Bremerhaven in January/February 2003 (Warneke et al., 2005) (the ship track is shown in Fig. 8e). In that study agreement within $\sim 5 \%$ has been found for measurements over land (Africa). For the SCIAMACHY measurements over the Atlantic Ocean (closer to the ship track) larger deviations (scatter) are found. This is expected because of the low surface spectral reflectance of the ocean and the resultant low signal-to-noise ratio for the spectra. Several days of SCIAMACHY methane columns have been compared with five land based FTS ground stations having a precision of $\sim 1-3 \%$ and an accuracy of $\sim 10 \%$ for methane columns (de Maziere et al., 2004). The agreement is typically within $15 \%$. It is however difficult to draw firm conclusions from that study due to the small number of good cloud free coincidences, because some stations are located on mountains (Jungfraujoch, Zugspitze) only observing overhead columns, or are located near the coast (Lauder) which is problematic due to the lower quality of the SCIAMACHY near-infrared/nadir measurements over water.

The $\mathrm{CO}_{2}$ and $\mathrm{CH}_{4}$ data products have been compared with global models of atmospheric transport and chemistry. This is an important step in assessing the quality of the data products: validation by comparison with independent measurements being limited by the number of ground stations.

The WFM-DOAS v0.4 methane and carbon dioxide columns and models, discussed in this manuscript, are planned in the longer term to be used to infer information about the surface sources and sinks of the greenhouse gases $\mathrm{CH}_{4}$ and $\mathrm{CO}_{2}$ (e.g. within the European Commission 5th framework research project EVERGREEN, see http://www. knmi.nl/evergreen) by means of inverse modelling. Because the surface sources and sinks only result in a weak modulation of the background columns, this application requires high accuracy and precision (see discussion given above).

WFM-DOAS is a scientific algorithm independent of the official operational algorithm of ESA/DLR which is under development. In this context it is important to point out that other groups are also working on scientific retrieval algorithms using different approaches (see Gloudemans et al., 2004; Frankenberg et al., 2005).

This paper is organised as follows: In Sect. 2 the SCIAMACHY instrument is introduced followed by a short description of how the spectra are pre-processed to improve the calibration (Sect. 3). The WFM-DOAS retrieval algorithm is introduced in Sect. 4. Section 5 discusses the altitude sensitivity of the SCIAMACHY measurements. The cloud identification scheme is explained in Sect. 6. In Sect. 7 spectral WFM-DOAS fit are presented and discussed. A short overview about the models used for the comparison is given 
in Sect. 8. In Sect. 9 the SCIAMACHY data are compared with the corresponding model results. The conclusions are given in Sect. 10.

\section{The SCIAMACHY instrument}

The SCanning Imaging Absorption spectroMeter for Atmospheric CHartographY (SCIAMACHY) instrument (Burrows et al., 1995; Bovensmann et al., 1999, 2004) is part of the atmospheric chemistry payload of the European Space Agencies (ESA) environmental satellite ENVISAT, launched in March 2002. The SCIAMACHY objectives and instrument concept were developed between 1984 and 1988 and proposed to ESA for flight on the ESA polar platform in July 1988, subsequently renamed ENVISAT. This proposal was supported by the German space agency (DLR). In February 1989, SCIAMACHY was selected as a national contribution after peer review for its Phase A study. Subsequently the relevant Dutch and Belgian space agencies, joined the consortium developing and providing SCIAMACHY to ESA for ENVISAT.

ENVISAT flies in sun-synchronous polar low Earth orbit crossing the equator at 10:00 a.m. local time. SCIAMACHY is a grating spectrometer that measures spectra of scattered, reflected, and transmitted solar radiation in the spectral region $240-2400 \mathrm{~nm}$ in nadir, limb, and solar and lunar occultation viewing modes. The SCIAMACHY near-infrared (NIR) nadir spectra contain information about many important atmospheric trace gases such as $\mathrm{CH}_{4}, \mathrm{CO}_{2}, \mathrm{CO}$, and $\mathrm{N}_{2} \mathrm{O}$.

For this study observations from channel 4 (for $\mathrm{O}_{2}$ ), channel 6 (for $\mathrm{CO}_{2}$ ) channel 8 (for $\mathrm{CH}_{4}$ ), and Polarisation Measurement Device (PMD) number $1(\sim 320-380 \mathrm{~nm})$ have been used. Channels 4, 6 and 8 measure simultaneously the spectral regions $600-800 \mathrm{~nm}, 970-1772 \mathrm{~nm}$ and 2360 $2385 \mathrm{~nm}$ at spectral resolutions of $0.4,1.4$ and $0.2 \mathrm{~nm}$, respectively. For channel 8 data, the spatial resolution, i.e. the footprint size of a single nadir measurement, is $30 \times 120 \mathrm{~km}^{2}$ corresponding to an integration time of $0.5 \mathrm{~s}$, except at high solar zenith angles (e.g. polar regions in summer hemisphere), where the pixel size is twice as large $\left(30 \times 240 \mathrm{~km}^{2}\right)$. For channel 4 and 6 the integration time is smaller, i.e. $0.25 \mathrm{~s}$, and corresponds to $30 \times 60 \mathrm{~km}^{2}$. SCIAMACHY also performs direct (extraterrestrial) sun observations mainly to obtain the solar reference spectra needed for the retrieval. The in-flight optical performance of SCIAMACHY is overall as expected from the on-ground calibration and characterisation activities (Bovensmann et al., 2004). One exception is the time dependent optical throughput variation in the SCIAMACHY NIR channels 7 and 8 due to ice build-up. This effect is minimised by regular heating of the instrument (Bovensmann et al., 2004) and further discussed in Sect. 9.1.

\section{Pre-processing of SCIAMACHY spectra}

The SCIAMACHY spectra used for this study are the ENVISAT operational Level 1 data products. The calibration is currently not optimal (especially in the NIR). During the commissioning phase of ENVISAT in the first six months of the mission in space, the planned in-orbit dark signal measurement strategy was identified as being inadequate. As a result improved dark signal measurements began at the end of 2002. These improved measurements are made more frequently (every orbit) and with pixel exposure (readout) times which better match the exposure times of the daytime nadir measurements. They are included in the Level 1 data products but are not used by the version of the Level 0-1 processor available for this study. For this study, the binary Level 1 data files have been "patched", i.e. the standard dark signals have been replaced by the improved ones. This has resulted in significantly better WFM-DOAS fits, as expected. In order to further improve the calibration, non linearities in the analogue to digital converter (ADC) are taken into account (Kleipool, 2003). Nevertheless, there is still room for improvements with respect to the dark signal correction as the variation of the dark signal over the orbit is not yet taken into account.

Especially the channel 8 detector array is very inhomogeneous with respect to detector pixel properties, such as quantum efficiency and dark signal, which vary strongly from pixel to pixel. Thus bad and dead pixels are not included in data product retrieval. We have extended the "dead pixels mask" of the Level 1 data product to reject individual pixels inducing strong (from several percent up to several ten percent) spikes (positive or negative signal deviations from the signals of the adjacent pixels) in the solar irradiance and/or nadir radiance spectra.

As the calibration of the solar reference spectra as contained in the Level 1 data products is also preliminary, a solar reference spectrum with an improved calibration has been used. This spectrum has been generated and made available by ESA (provided by J. Frerick, ESA/ESTEC).

\section{The WFM-DOAS retrieval algorithm}

\subsection{Description of the method}

The Weighting Function Modified Differential Optical Absorption Spectroscopy (WFM-DOAS) retrieval algorithm has been developed primarily for the retrieval of the total column amounts of $\mathrm{CO}, \mathrm{CH}_{4}, \mathrm{CO}_{2}, \mathrm{H}_{2} \mathrm{O}$, and $\mathrm{N}_{2} \mathrm{O}$, from the SCIAMACHY NIR nadir spectra (Buchwitz et al., 2000a, 2004; Buchwitz and Burrows, 2004). WFM-DOAS, however, is not limited to this application and has also been successfully applied to ozone total column retrieval using GOME data (Coldewey-Egbers et al., 2004) and to water 
vapour retrieval using GOME and SCIAMACHY nadir spectra around $700 \mathrm{~nm}$ (Noël et al., 2004).

Any algorithm that aims at retrieving atmospheric information from global satellite data not only has to be accurate but also has to be sufficiently fast in order to be able to process huge amounts of data (SCIAMACHY spectra comprise about 8000 data points, which are recorded several times per second corresponding to a data rate of 400 kbit per second). Accuracy and speed are conflicting requirements and an appropriate compromise has to be found. The WFM-DOAS algorithm in its current implementation (look-up table approach) as described in this section is very fast. The processing of an entire orbit of pre-processed SCIAMACHY spectra (see Sect. 3) requires a couple of minutes per fitting window on a standard single processor $\mathrm{PC}$, which is more than one order of magnitude faster than real time (one orbit lasts about $100 \mathrm{~min}$ ).

WFM-DOAS is based on fitting the logarithm of a linearised radiative transfer model $I^{\text {mod }}$ plus a low-order polynomial $P$ to the logarithm of the ratio of a measured nadir radiance and solar irradiance spectrum, i.e. observed sunnormalised radiance $I^{o b s}$. The linear least-squares WFMDOAS equation can be written as follows (fit parameters are underlined):

$$
\left\|\ln I_{i}^{o b s}-\ln I_{i}^{m o d}(\underline{\hat{\mathbf{V}}})\right\|^{2} \equiv\left\|R E S_{i}\right\|^{2} \rightarrow \min .
$$

where the linearised radiative transfer model is given by

$$
\begin{aligned}
\ln I_{i}^{\text {mod }}(\underline{\hat{\mathbf{V}}}) & =\ln I_{i}^{\bmod }(\overline{\mathbf{V}}) \\
+ & \left.\sum_{j=1}^{J} \frac{\partial \ln I_{i}^{\text {mod }}}{\partial V_{j}}\right|_{\bar{V}_{j}}\left(\underline{\hat{V}_{j}}-\bar{V}_{j}\right)+P_{i} \underline{\left(\underline{a_{m}}\right)} .
\end{aligned}
$$

Index $i$ refers to the canter wavelength $\lambda_{i}$ of detector pixel number $i$. The components of vectors $\boldsymbol{V}$, denoted $V_{j}$, are the vertical columns of all trace gases which have absorption lines in the selected spectral fitting window. The fit parameters are the desired trace gas vertical columns $\hat{V}_{j}$ and the polynomial coefficients $a_{m}$. An additional fit parameter also used (but omitted in Eqs. 1 and 2) is the shift (in Kelvin) of a pre-selected temperature profile. This fit parameter has been added in order to take the temperature dependence of the trace gas absorption cross-sections into account. The fit parameter values are determined by minimising (in a linear least-squares sense) the difference between observation $\left(\ln I_{i}^{o b s}\right)$ and WFM-DOAS model $\left(\ln I_{i}^{m o d}\right)$, i.e. fit residuum $R E S_{i}$, for all spectral points $\lambda_{i}$ simultaneously. A derivative, or weighting function, with respect to a vertical column refers to the change of the top-of-atmosphere radiance caused by a change (here: scaling) of a pre-selected trace gas vertical profile. The WFM-DOAS reference spectra are the logarithm of the sun-normalised radiance and its derivatives. They are computed with a radiative transfer model (Buchwitz et al., 2000b) for assumed (e.g. climatological) "mean" columns
$\overline{\mathbf{V}}$. Multiple scattering is fully taken into account. The leastsquares problem (Eqs. 1 and 2) can also be expressed in the following vector/matrix notation: Minimise $\|\mathbf{y}-\mathbf{A} \mathbf{x}\|^{2}$ with respect to $\mathbf{x}$. The solution is $\hat{\mathbf{x}}=\mathbf{C}_{\mathbf{x}} \mathbf{A}^{T} \mathbf{y}$ where $\mathbf{C}_{\mathbf{x}} \equiv\left(\mathbf{A}^{T} \mathbf{A}\right)^{-1}$ is the covariance matrix of solution $\hat{\mathbf{x}}$. The errors of the retrieved columns are estimated as follows (Press et al., 1992): $\sigma_{\hat{V}_{j}}=\sqrt{\left(\mathbf{C}_{\mathbf{x}}\right)_{j j} \times \sum_{i} R E S_{i}^{2} /(m-n)}$, where $\left(\mathbf{C}_{\mathbf{x}}\right)_{j j}$ is the $j$ th diagonal element of the covariance matrix, $m$ is the number of spectral points in the fitting window and $n$ is the number of linear fit parameters $\left(R E S_{i}\right.$ is the spectral fit residuum, see Eq. 1).

In order to avoid time consuming on-line radiative transfer simulations, a look-up table approach has been implemented (see Buchwitz and Burrows, 2004, for details). The WFMDOAS reference spectra (radiance and derivatives) have been computed for cloud free conditions assuming a US Standard Atmosphere, a tropospheric maritime and stratospheric background aerosol scenario and a surface albedo of 0.1 . They depend on solar zenith angle, surface elevation $(0-3 \mathrm{~km}$ in steps of $1 \mathrm{~km}$ ), and water vapour column.

It is important to point out that no a priori information is used to constrain the retrieved columns, i.e., the retrieved columns are not forced to lie in a pre-defined interval. This however does not mean that the retrieved columns are independent on a priori information. As explained, a priori information on the atmosphere is used to get a reasonable linearisation point for the unconstrained linear least-squares WFM-DOAS fit.

\subsection{Error analysis}

The random error (precision) of the retrieved $\mathrm{CH}_{4}$ and $\mathrm{CO}_{2}$ columns due to instrument noise is $\sim 1 \%$ (1-sigma) for the spectral fitting windows used for this study (for an albedo of 0.1 and a solar zenith angle of $50^{\circ}$ ) (Buchwitz and Burrows, 2004). In addition to instrument noise a large number of other error sources contribute to the overall error such as errors resulting from the variability of temperature and water vapor profiles, aerosols, undetected sub-visual cirrus clouds, and albedo effects. The resulting errors are partially systematic and partially random, i.e., they influence both the precision (scatter) and the accuracy (bias) of the retrieved columns.

To quantify these errors an error analysis of the current implementation of the WFM-DOAS retrieval algorithm has been performed by applying WFM-DOAS to simulated nadir spectra (Buchwitz and Burrows, 2004). Table 1 summarises the most important results for the $\mathrm{CH}_{4}$ and $\mathrm{CO}_{2}$ columns and for the column averaged mixing ratios $\mathrm{XCH}_{4}$ and $\mathrm{XCO}_{2}$. In the following we will shortly discuss the results shown in Table 1. For details, e.g., about the aerosol scenarios and the model atmospheres, we refer to Buchwitz and Burrows (2004) and the references given therein. 
Table 1. Results of the error analysis performed by applying WFM-DOAS to simulated SCIAMACHY measurements for the retrieval of $\mathrm{CH}_{4}, \mathrm{CO}_{2}$, and $\mathrm{O}_{2}$ columns as well as for the $\mathrm{O}_{2}$ column normalized mixing ratios $\mathrm{XCH}_{4}$ and $\mathrm{XCO}_{2}$. The results are valid for a solar zenith angle of $50^{\circ}$. The errors on the columns are the relative difference of the retrieved columns and the known columns of the model atmosphere. The $\mathrm{XCH}_{4}$ error has been calculated from the listed relative error of the $\mathrm{CH}_{4}$ column $\left(\epsilon_{\mathrm{CH}}\right)$ and the relative error of the $\mathrm{O}_{2}$ column $\left(\epsilon_{O 2}\right)$ as follows: $\epsilon_{X C H 4}=\left(\left(1+\epsilon_{C H 4}\right) /\left(1+\epsilon_{O 2}\right)-1\right)$. The $\mathrm{XCO}_{2}$ error has been calculated analogously. Details concerning the radiative transfer simulations performed to obtain the errors are given in Buchwitz and Burrows (2004). The acronyms and abbreviations have the following meaning: Profiles: USS: US standard atmosphere profiles; "ref.": reference atmosphere for WFM-DOAS radiative transfer simulations (because the retrieval is self consistent the corresponding retrieval errors are zero), SAS: profiles of sub-arctic summer atmosphere, SAW: sub-arctic winter, MLS: mid-latitude summer, TRO: tropical atmosphere. Aerosols: DEF: WFM-DOAS default aerosol scenario (maritime aerosol in the boundary layer and background stratosphere), OAC: OPAC Average Continental aerosol scenario. ASOD is the aerosol scattering optical depth at $2 \mu \mathrm{m}$. Sub-visual cirrus clouds: SOD: scattering optical depth (wavelength independent)

\begin{tabular}{lrrrrr}
\hline Error source & $\begin{array}{r}\mathrm{CH}_{4} \text { column } \\
\text { error }(\%)\end{array}$ & $\begin{array}{r}\mathrm{CO}_{2} \text { column } \\
\text { error (\%) }\end{array}$ & $\begin{array}{r}\mathrm{O}_{2} \text { column } \\
\text { error (\%) }\end{array}$ & $\begin{array}{r}\mathrm{XCH}_{4} \\
\text { error (\%) }\end{array}$ & $\begin{array}{r}\mathrm{XCO}_{2} \\
\text { error (\%) }\end{array}$ \\
\hline Profiles (Temp., ${ }_{2} \mathrm{O}$, etc.): & & & & & \\
USS (ref.) & 0.0 & 0.0 & 0.0 & 0.0 & 0.0 \\
SAS & 1.3 & 0.0 & 0.0 & 1.3 & 0.0 \\
SAW & 1.1 & 0.1 & 0.4 & 0.7 & -0.3 \\
MLS & 0.9 & -0.1 & 0.1 & 0.8 & -0.2 \\
MLW & 1.2 & 0.4 & 0.8 & 0.4 & -0.4 \\
TRO & -0.4 & -0.4 & 0.0 & -0.4 & -0.4 \\
\hline Aerosols: & & & & & \\
DEF (ASOD: 0.15) (ref.) & 0.0 & 0.0 & 0.0 & 0.0 & 0.0 \\
OAC (ASOD: 0.04) & -0.3 & -0.5 & -0.5 & 0.2 & 0.0 \\
No aerosol (ASOD: 0.00$)$ & -0.3 & -0.8 & -2.5 & 2.3 & 1.7 \\
\hline Sub-visual cirrus at 12 km: & & & & & \\
SOD 0.00 (ref.) & 0.0 & 0.0 & 0.0 & 0.0 & 0.0 \\
SOD 0.01 & -1.1 & -0.4 & 1.1 & -2.2 & -1.5 \\
SOD 0.02 & -2.4 & -0.8 & 2.0 & -4.3 & -2.7 \\
\hline Albedo: & & & & & \\
0.30 & 0.8 & 1.4 & -3.0 & 3.9 & 4.5 \\
0.20 & 0.5 & 0.9 & -1.5 & 2.0 & 2.4 \\
0.10 (ref.) & 0.0 & 0.0 & 0.0 & 0.0 & 0.0 \\
0.05 & -0.7 & -1.3 & -2.1 & 1.4 & 0.8 \\
0.03 & -1.5 & -2.6 & -6.3 & 5.1 & 3.9 \\
\hline
\end{tabular}

To estimate the errors originating from the variability of temperature and trace gas vertical profiles (mainly water vapor) simulated spectra have been generated using various model atmospheres (using the same pressure profile). As can be seen in Table 1, the errors are typically below $1 \%$ for the columns and for the ratio of the greenhouse gas columns with the $\mathrm{O}_{2}$ column, i.e., for $\mathrm{XCH}_{4}$ and $\mathrm{XCO}_{2}$. The errors due to temperature profile variations are relatively small because a weighting function for a temperature profile shift is included in the retrieval. Errors due to water vapor profile variations are also quite small because a weighting function for water absorption is included in the fit and because the spectral fitting windows have been selected such that interference with water vapor absorption is small.

Due to scattering, aerosols and (cirrus) clouds influence the (average) light path of the detected solar photons and, therefore, influence not only the overall level of the backscat- tered radiance (which is considered by the polynomial included in the WFM-DOAS fit) but also the relative depth of the absorption lines of the gases. This introduces an error. Unfortunately, this error is not the same for the greenhouse gases and for $\mathrm{O}_{2}$ as scattering depends on wavelength. Scattering gets more important the shorter the wavelength (note that $\mathrm{O}_{2}$ is retrieved from the $760 \mathrm{~nm}$ spectral region, $\mathrm{CO}_{2}$ from the $1580 \mathrm{~nm}$ region, and $\mathrm{CH}_{4}$ from the $2270 \mathrm{~nm}$ region). If these errors would be the same for all gases they would cancel if the ratio with the $\mathrm{O}_{2}$ column is computed, i.e., for $\mathrm{XCH}_{4}$ and $\mathrm{XCO}_{2}$. Unfortunately, this is not always the case. The error on the retrieved $\mathrm{O}_{2}$ column may even have an opposite sign compared to the error on the greenhouse gases (see, e.g., sub-visual cirrus scenarios). This is because an albedo weighting function is included in the $\mathrm{O}_{2}$ fit which is not included in the $\mathrm{CH}_{4}$ and $\mathrm{CO}_{2}$ fits. The albedo weighting function has been included in the $\mathrm{O}_{2}$ fit to reduce (very) 

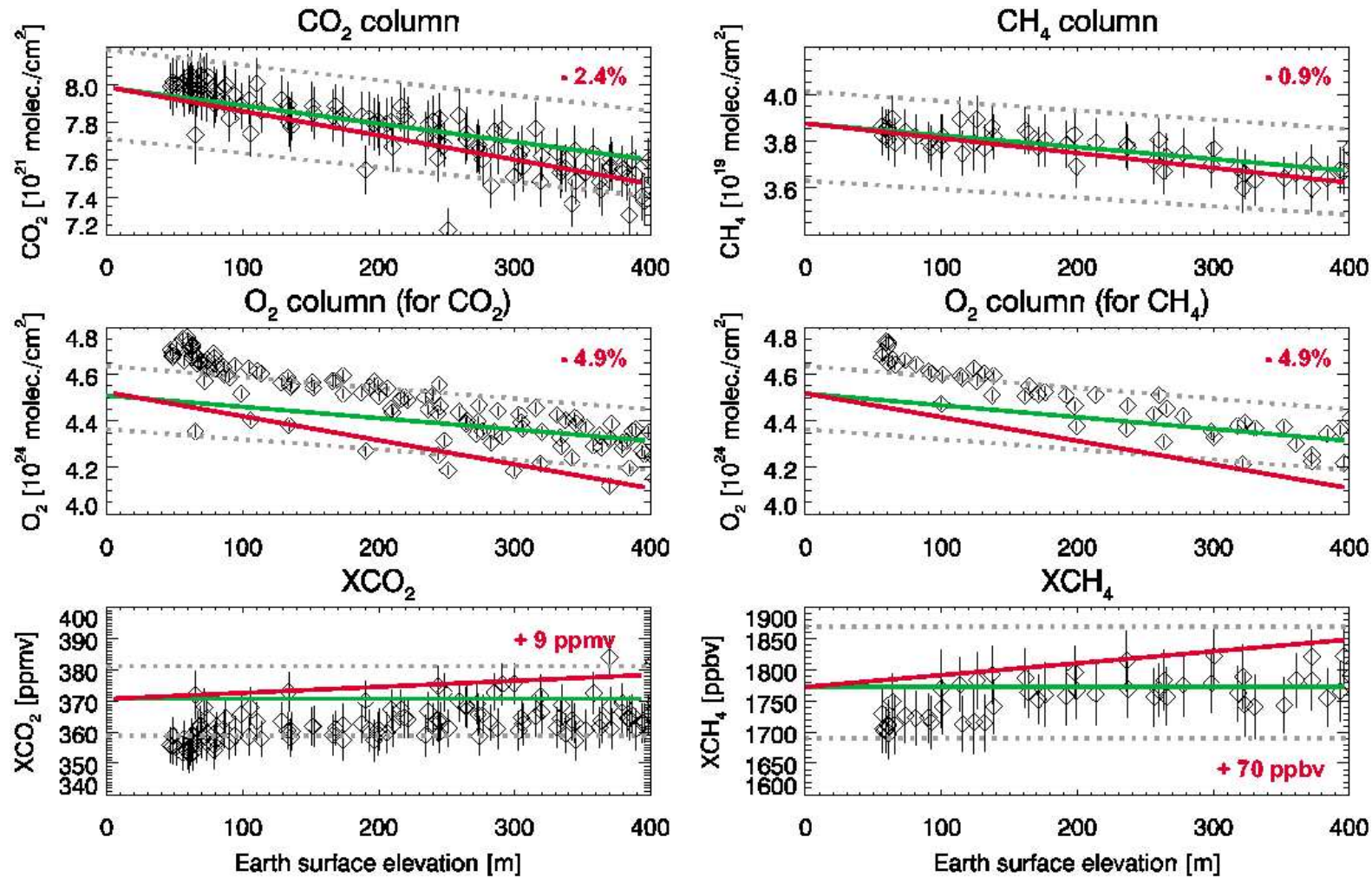

Fig. 1. Correlation of the $\mathrm{CO}_{2}, \mathrm{CH}_{4}$, and $\mathrm{O}_{2}$ columns as retrieved from SCIAMACHY measurements around Senegal on 23 January 2003 with the surface elevation of the corresponding ground pixels. The black symbols are the retrieved columns and the black vertical lines are the fit errors (see Sect. 4). The green lines show the expected values for the columns computed using a standard pressure profile. The dotted lines indicate their estimated variability $\left( \pm 3 \%\right.$ for $\mathrm{CO}_{2}$ and $\mathrm{O}_{2}, \pm 5 \%$ for $\mathrm{CH}_{4}$ ). The red lines have been determined from simulated retrievals (see main text for details). The numbers given at the right hand side of each panel show the column retrieval error for $400 \mathrm{~m}$ surface elevation as determined from simulated retrievals (figure adapted from Buchwitz and Burrows, 2004).

large $\mathrm{O}_{2}$ errors resulting from albedo variations (Buchwitz and Burrows, 2004). The errors due to albedo variability of the currently implemented retrieval algorithm are listed in Table 1. The error is zero for an albedo of 0.1 (because this the albedo assumed for WFM-DOAS retrievals which are self consistent) but can be as large as a few percent for ground pixels with much lower or much higher albedo. This error needs to be reduced in future versions of the retrieval algorithm, e.g., by estimating the surface albedo from the SCIAMACHY measurements and using a look-up table that also depends on surface albedo.

An error source not discussed in detail in Buchwitz and Burrows (2004) is the influence of the pressure profile on the retrieved columns, most notably the error due to surface pressure variations. If an incorrect pressure profile (with a wrong surface pressure) is used for the retrieval an error is introduced because the absorption cross sections (line shapes) of the trace gases depend on pressure. This influences the retrieval although the spectral resolution of SCIAMACHY is typically not high enough to resolve individual lines. Figure 1 shows $\mathrm{CO}_{2}, \mathrm{CH}_{4}$, and $\mathrm{O}_{2}$ columns as retrieved from SCIAMACHY for a cloud free scene near Senegal, Africa, on 23 January 2003. The columns are plotted as a function of the ground height (the height above sea level obtained from a surface topography database) of the corresponding nadir ground pixels. For a standard pressure profile the pressure drops by about $1.2 \%$ per $100 \mathrm{~m}$ altitude increase. This corresponds to an air column decrease of $1.2 \%$ per $100 \mathrm{~m}$ ground pixel height increase. For the relatively long-lived and therefore well-mixed gases $\mathrm{CH}_{4}$ and $\mathrm{CO}_{2}$ this corresponds to a column decrease of $\sim 1.2 \%$ per $100 \mathrm{~m}$ altitude increase. Figure 1 shows that small column variations $(\sim 1 \%)$ due to small surface elevation changes $(\sim 100 \mathrm{~m})$ can in fact be observed with SCIAMACHY to a high degree of accuracy. The measurements shown in Fig. 1 demonstrate the theoretically predicted sensitivity of SCIAMACHY to small (partial column) $\mathrm{CH}_{4}$ and $\mathrm{CO}_{2}$ changes in the lower troposphere (see Sect. 5).

Figure 1, however, also shows that the dependence of the retrieved columns on surface elevation is somewhat larger than expected (slope of the green lines). This can be explained by the fact that a constant (US Standard Atmosphere) pressure profile is currently used in WFM-DOAS in combination with a look-up table that includes different surface elevations (surface pressures) but only on a coarse grid $(0,1$, 
2, and $3 \mathrm{~km}$ ). A simple next neighbour approach is currently used to select the reference spectra (radiance and derivatives) for a given ground pixel. Therefore, for ground pixels with an average surface elevation of less than $500 \mathrm{~m}$ (as shown in Fig. 1) identical WFM-DOAS reference spectra (those for 0 $\mathrm{km}$ ground height) are currently used (except for solar zenith angle interpolation). They have all been computed assuming a standard pressure profile with $1013 \mathrm{hPa}$ at the lowest level. The advantage of this approach is (apart from the fact that the look-up table is relatively small) that the variability of the retrieved columns, e.g. the variability shown in Fig. 1, is entirely due to the spectral measurements of SCIAMACHY and does not result from any a priori information. Because all the reference spectra are identical it is thereby ensured that no artificial variability is mixed into the measured (!) columns by using a priori information in the retrieval process. The red lines shown in Fig. 1 have been determined by applying WFM-DOAS to simulated measurements computed with the same profiles (including the pressure profile) as used for the generation of the look-up table but with a lower boundary equal to the surface elevation of the corresponding ground pixels and, therefore, with the correct surface pressure. As can be seen, the dependence of the retrieved columns and mixing ratios on the surface elevation is better represented by the slopes of the corresponding red lines than by the slopes of the green lines. This shows that the "slope error" seen in Fig. 1 can in fact be explained by the use of a constant pressure profile. This error source needs to be minimised in future versions of WFM-DOAS. This, however, is not trivial if one wants to avoid the use of highly correlated a priori information (e.g., surface pressure from meteorological analysis) with errors on the order of (or even significantly larger than) the weak surface source/sink signal to be detected.

\section{Sensitivity to boundary layer $\mathrm{CH}_{4}$ and $\mathrm{CO}_{2}$}

One significant advantage of the near-IR spectral region, in contrast to, e.g. the thermal IR region, for the detection of greenhouse gas columns is that the radiation detected by a nadir viewing satellite instrument is highly sensitive to trace gas concentration changes in the boundary layer. This is important as the concentration variation due to sources and sinks is largest in the lower troposphere and, therefore, this region must be probed in order to get accurate information on surface sources and sinks.

This sensitivity is theoretically demonstrated for SCIAMACHY $\mathrm{CH}_{4}$ and $\mathrm{CO}_{2}$ observations, by computing the $\mathrm{CH}_{4}$ and $\mathrm{CO}_{2}$ vertical column averaging kernels, which are shown in Fig. 2. For this purpose WFM-DOAS has been applied to simulated nadir spectra generated for an unperturbed as well as for perturbed greenhouse gas profiles. A perturbed $\mathrm{CH}_{4}$ or $\mathrm{CO}_{2}$ profile has been generated from the unperturbed profiles by adding a certain (constant) number of $\mathrm{CH}_{4}$ or $\mathrm{CO}_{2}$ molecules at a given alti- tude level. The averaging kernels (AK) are defined as follows: $A K\left(z_{i}\right) \equiv\left(V^{r p}-V^{r u}\right) /\left(V^{t p}-V^{t u}\right)$, where $V^{t u}$ is the true greenhouse column for the unperturbed greenhouse profile, $V^{r u}$ is the retrieved greenhouse column for the unperturbed greenhouse profile, and $V^{t p}$ and $V^{r p}$ are the true and retrieved columns for the perturbed profiles (having an enhanced greenhouse gas concentration at altitude $z_{i}$ ), respectively. $A K\left(z_{i}\right)$ is the $i$-th element of the averaging kernel, which is a vector. The altitude $z_{i}$ is the altitude where the trace gas profile has been perturbed. The true column $V^{t u}$ is the column of the standard model atmosphere. To illustrate this: A value of the column averaging kernel of 1.2 at $5 \mathrm{~km}$ means that if, for example, 100 molecules (per volume element) are added at $5 \mathrm{~km}$ (to the standard profile), 120 additional molecules are retrieved, which is an overestimation of $20 \%$ (not of the total column but) of the difference between the true profile and the standard (or a priori) profile. If the true profile has lower values than the standard profile the retrieved column will be underestimated accordingly. We have verified that WFM-DOAS retrievals are self-consistent, i.e., that the retrieved column $V^{r u}$ for the unperturbed profile is numerically equal to the true column $V^{t u}$ of the unperturbed profile.

Due to the fact that the SCIAMACHY/WFM-DOAS averaging kernels are "imperfect" in the sense that they deviate from unity, a so-called smoothing error will result for the retrieved columns. This smoothing error has been estimated by Connor et al. (2003) for the $\mathrm{CO}_{2}$ measurements of SCIAMACHY and other instruments using an optimal estimation profile retrieval algorithm. For SCIAMACHY the estimated $\mathrm{CO}_{2}$ column smoothing error is $0.5 \mathrm{ppmv}$ (the results for the other instruments are: AIRS on Aura: $1.5 \mathrm{ppmv}$, planned OCO instrument: 0.3 ppmv, ground based FTS: $0.01 \mathrm{ppmv}$ ). These values are valid for an optimal estimation profile retrieval algorithm. For WFM-DOAS retrievals the smoothing error is expected to be somewhat larger because of the larger deviation of the averaging kernels from unity.

For altitudes where the averaging kernels are significantly larger than zero (where they are on the order of 1.0) the measurement system, here SCIAMACHY, is sensitive to concentration changes. In this context it has to be noted that the exact value of the averaging kernel not only depends on the instrument but also on the retrieval algorithm. The averaging kernels shown here are valid for the WFM-DOAS algorithm as used for this study. They will be different for different algorithms (i.e. WFM-DOAS, which is based on scaling entire profiles, has other averaging kernels than, for example, an optimal estimation profile retrieval algorithm, which has more degrees of freedom). These remarks refer to the details of the averaging kernels, not however to some general conclusions about the sensitivity to the lower atmosphere which can be drawn independently of any retrieval algorithm. This is because qualitatively the altitude sensitivity can be assessed without using averaging kernels simply by computing the derivatives of the top of atmosphere radiance with respect 

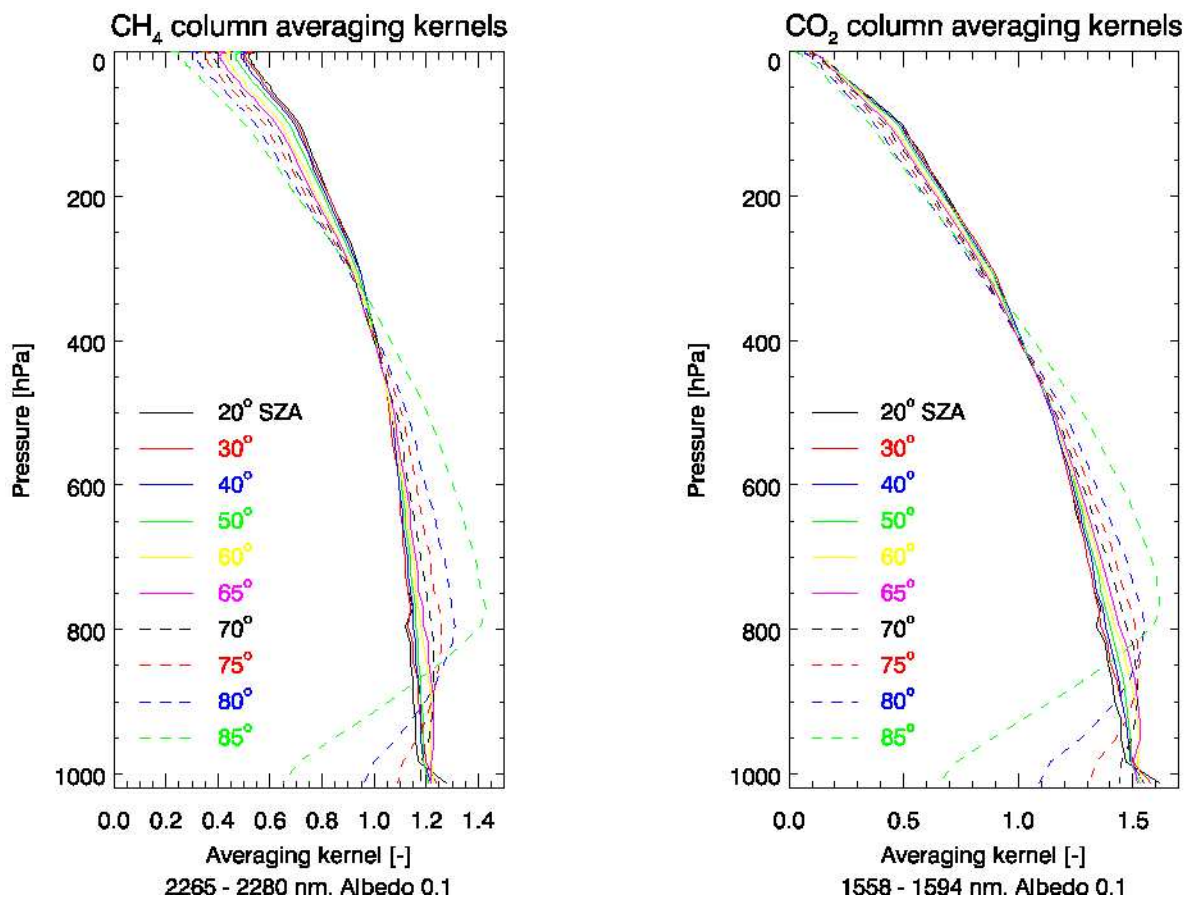

Fig. 2. SCIAMACHY averaging kernels for WFM-DOAS retrievals of $\mathrm{CH}_{4}$ columns (left) and $\mathrm{CO}_{2}$ columns (right). The averaging kernels have been computed by applying WFM-DOAS to simulated spectra for various solar zenith angles.

to concentration changes at the altitudes of interest. These derivatives (which are not shown here) are consistent with the averaging kernels shown in Fig. 2. They show, for example, that the sensitivity decreases with increasing perturbation altitude which is consistent with the averaging kernels shown in Fig. 2. This is typical for relatively strong absorption lines and is due to saturation of unresolved lines in the strong absorber limit (Goody and Yung, 1989) which gets more important the narrower (i.e. the less pressure broadened) the lines are.

The SCIAMACHY/WFM-DOAS averaging kernels for $\mathrm{CH}_{4}$ and $\mathrm{CO}_{2}$ shown in Fig. 2 indicate that the sensitivity of the SCIAMACHY nadir measurements for solar zenith angles less than $\sim 70^{\circ}$ is high (larger than 0.5 ) at all altitudes below $\sim 100 \mathrm{hPa}(\sim 16 \mathrm{~km})$, including the boundary layer.

\section{Cloud identification}

The WFM-DOAS algorithm as described in Sect. 4 is strictly speaking only appropriate for cloud free scenes. As cloud contamination results in errors on the retrieved columns it is important to at least identify the cloud free pixels. For this purpose a cloud mask is generated ( 0 : pixel probably cloud free, 1: pixel probably cloud contaminated).

Currently, this cloud mask is generated using the subpixel information provided by SCIAMACHY's Polarisation Measurement Device (PMD) number 1 covering approximately the spectral region 320-380 nm (Bovensmann et al.,
1999). A simple single threshold algorithm is used. This algorithm does not specifically detect clouds but enhanced UV backscatter which results from clouds but also from enhanced aerosols and higher than average surface reflectivity (e.g. due to ice and snow). The algorithm works as follows: First, each interpolated PMD 1 readout as contained in the Level 1 file (32 values per one second integration time) that corresponds to a given (main channel) ground pixel is divided by the cosine of the solar zenith angle to obtain a quantity approximately proportional to top-of-atmosphere reflectivity. If this "PMD 1 reflectivity" is higher than a pre-defined threshold the corresponding sub-pixel is assumed to be cloud contaminated. A (main channel) ground pixel is flagged cloud contaminated if at least one of its PMD sub-pixels is cloud contaminated.

PMD 1 has been selected for the cloud mask generation because the scattered and reflected solar UV radiation detected by SCIAMACHY's nadir mode penetrates deep into the atmosphere (that is, the average scattering height is located close to the Earth surface) but the sensitivity to the Earth surface is significantly lower than for the other PMD channels covering parts of the visible and NIR spectral regions because scattering in the atmosphere decreases with increasing wavelength. This effect can be seen when comparing global maps showing the signal of the various PMDs. For example, a land to sea contrast is (nearly) not visible for PMD 1 but clearly visible for the other PMDs (not shown here). The threshold has been determined empirically by 


\section{PMD1 24-Jan-2003}

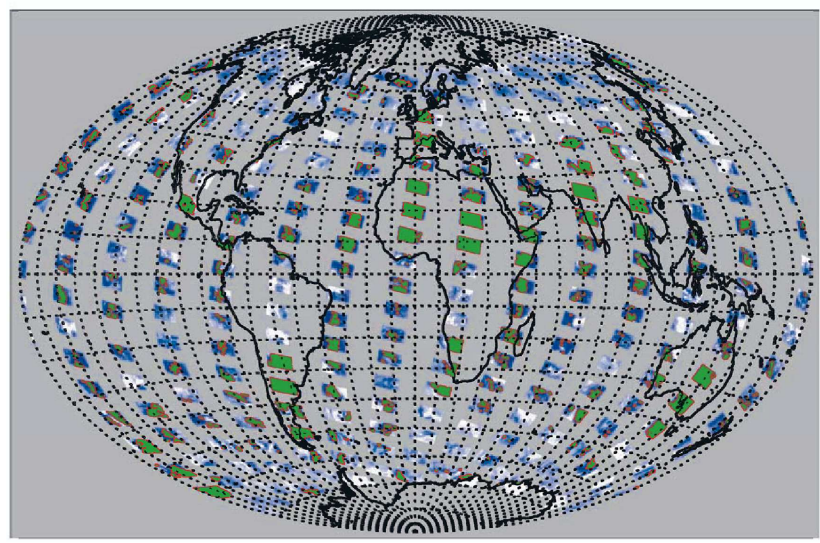

Fig. 3. Map of SCIAMACHY PMD 1 nadir reflectivity for 24 January 2003. The colors have the following meaning: White corresponds to high PMD signal (e.g. due to clouds) and dark blue to low signal. Pixels with a signal below a given threshold are interpreted as cloud free. These pixels are shown in green. The contours of the green areas are shown in red. These red contour lines are also shown on top of the MODIS image from the same day shown in Fig. 4. Large cloud free regions have been identified over northern Africa, India, south-east Asia, over the southern part of South America, and Australia.

visual inspection of global maps of PMD reflectivities overlaid with cloud masks generated for various thresholds. As an example, Fig. 3 shows a PMD 1 map for 24 January 2003. The value of the threshold has been selected as low as possible to avoid cloud contamination as good as possible. Selecting a slightly lower threshold would result in nearly all pixels being classified as "possibly cloud contaminated" (see Fig. 10).

To verify the PMD algorithm the SCIAMACHY data have been compared with regional and global radiance or reflectivity maps of other sensors such as AVHRR/NOAA and MODIS/Terra. As an example Fig. 4 shows the daily reflectance data product of MODIS/Terra for 24 January 2003. The MODIS image has been overlaid with the cloud free areas as determined from the SCIAMACHY data shown in Fig. 3. Figure 4 shows good agreement between the cloud free areas as determined with the SCIAMACHY PMD algorithm and the cloud free areas visible in the MODIS image. As can be seen, even small cloud free regions located within or at the edge of large complex cloud fields have been detected. The comparison also shows that there still might be some small scale clouds in the SCIAMACHY pixels not detected by the PMD algorithm. This needs further investigation taking into account the time difference between the sensors (the local equator overpass time is 10:00 a.m. for ENVISAT and 10:30 a.m. for Terra). The dependence of the measured $\mathrm{XCO}_{2}$ on the PMD threshold is discussed in Sect. 9.2. As the relatively simple PMD algorithm currently
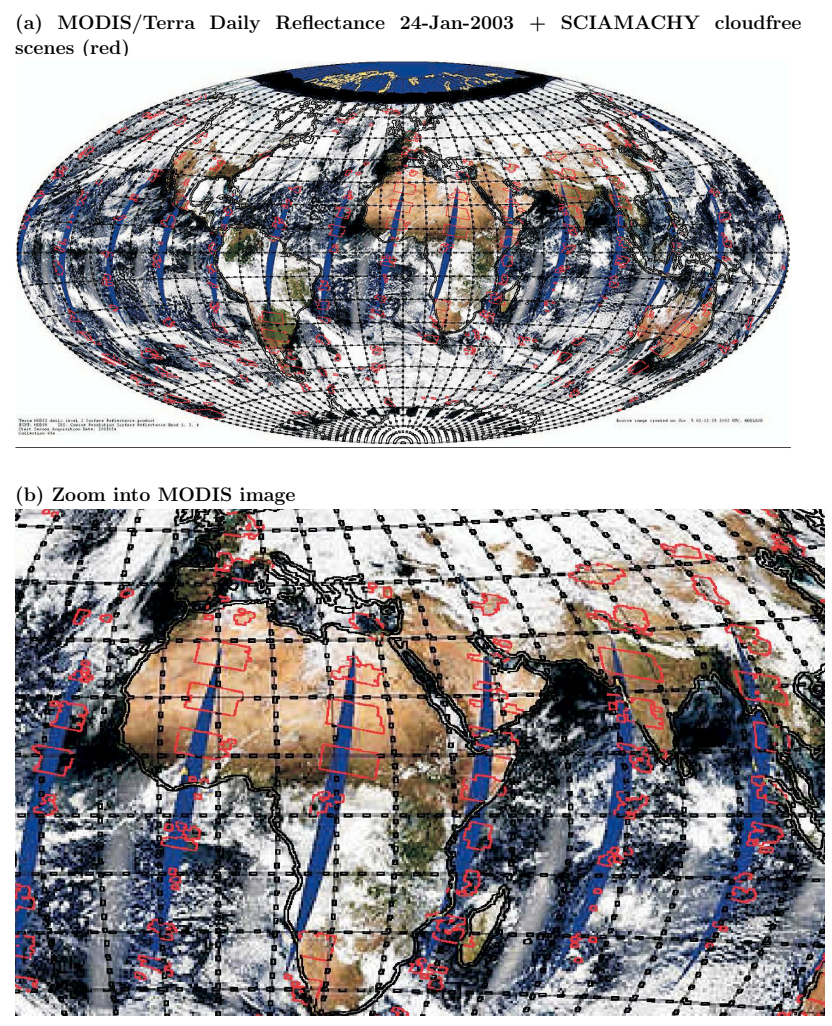

Fig. 4. (a) MODIS/Terra daily reflectance data product for 24 January 2003, i.e., for the same day as the PMD image shown in Fig. 3 (Source: http://landqa2.nascom.nasa.gov). The cloud free scenes as determined from the SCIAMACHY PMD data are shown as red contour lines. (b) Zoom into the image shown in panel (a).

used to identify cloud free scenes has already been tuned to be as conservative as possible it needs to be investigated if a more complex algorithm needs to be developed to avoid even small cloud contamination. This algorithm should also be able to discriminate between clouds and snow/ice covered surfaces. This can probably be achieved using a combination of various PMDs covering not only the UV but also parts of the visible and near-infrared as observed by SCIAMACHY.

\section{Methane and carbon dioxide WFM-DOAS fits}

Figure 5 shows typical $\mathrm{CH}_{4}, \mathrm{CO}_{2} \mathrm{O}_{2}$ WFM-DOAS fits. For $\mathrm{CH}_{4}$ a small spectral fitting window in SCIAMACHY channel 8 is used, for $\mathrm{CO}_{2}$ a small fitting window in channel 6 , and for $\mathrm{O}_{2}$ the $\mathrm{A}$ band located in channel 4. As can be seen, the spectral absorption structures of all three gases are clearly visible in the SCIAMACHY data and relatively good fits to the methane, carbon dioxide and oxygen absorption bands have been obtained. The root-mean-square (RMS) difference between the WFM-DOAS model and the SCIAMACHY measurement shown is $1.7 \%$ for the methane window, $0.7 \%$ for the $\mathrm{CO}_{2}$ window, and $1.3 \%$ for the $\mathrm{O}_{2}$ window. 

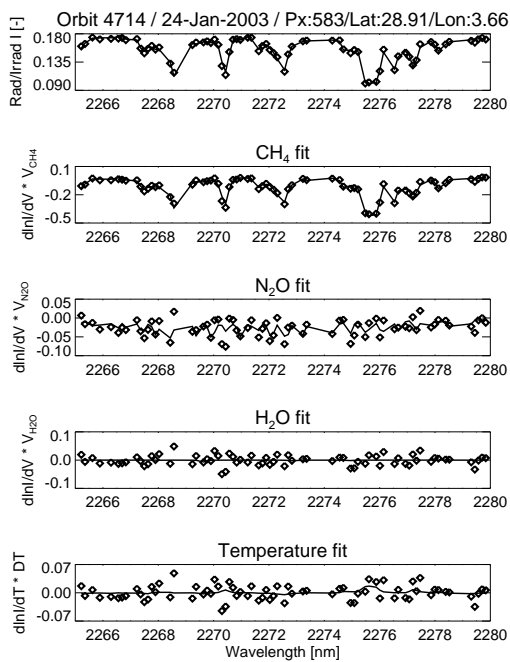
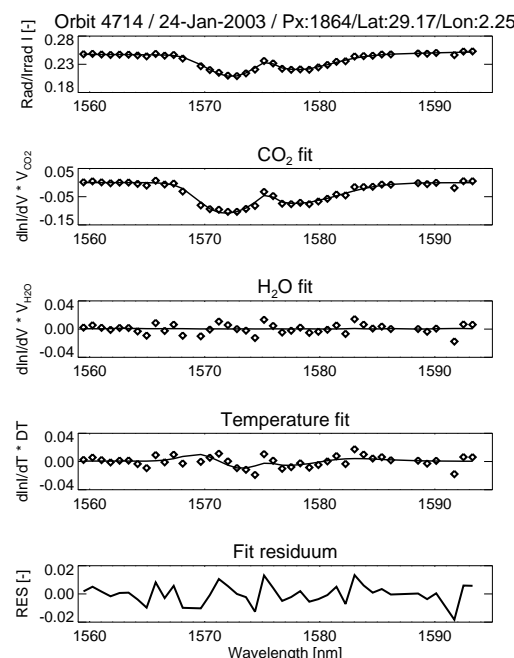
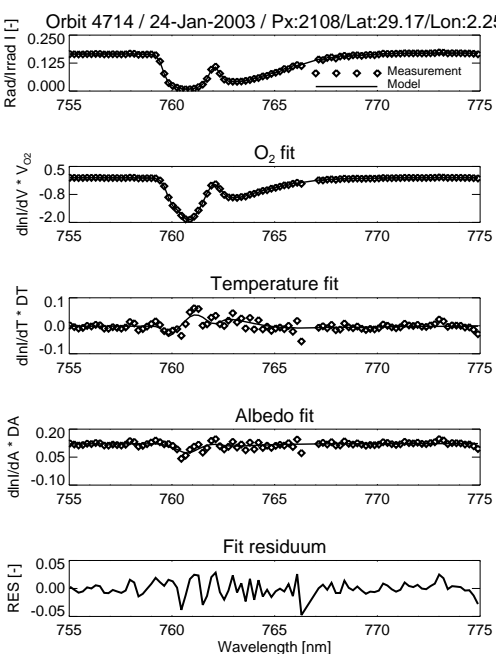

Fig. 5. Typical WFM-DOAS fits for methane (left), $\mathrm{CO}_{2}$ (middle), and $\mathrm{O}_{2}$ (right). Methane (left): The SCIAMACHY sun-normalised nadir spectrum (symbols) and the WFM-DOAS model spectrum (solid line) is shown in the top panel. The other panels show the fit results for the individual fit parameters, e.g. methane (second panel). The retrieved methane column is $3.59 \times 10^{19}$ molecules $/ \mathrm{cm}^{2} \pm 3 \%$. In addition to methane, $\mathrm{N}_{2} \mathrm{O}$ and $\mathrm{H}_{2} \mathrm{O}$ (both are weak absorber in this spectral region) and a shift of the temperature profile are included in the fit (see Buchwitz and Burrows, 2004, for details). The retrieved $\mathrm{N}_{2} \mathrm{O}$ column is $6.2 \times 10^{18}$ molecules $/ \mathrm{cm}^{2} \pm 22 \%$. The root-mean-square (RMS) difference between measurement and WFM-DOAS model is $0.017(1.7 \%)$. Middle: As left panel but for $\mathrm{CO}_{2}$. The retrieved $\mathrm{CO}_{2}$ column is $8.11 \times 10^{21}$ molecules $/ \mathrm{cm}^{2} \pm 6 \%$. The root-mean-square (RMS) difference between measurement and WFM-DOAS model is 0.0066 $(0.66 \%)$. Right: As left panel but for $\mathrm{O}_{2}$. The retrieved $\mathrm{O}_{2}$ column is $4.58 \times 10^{24}$ molecules $/ \mathrm{cm}^{2} \pm 1.4 \%$. The root-mean-square (RMS) difference between measurement and WFM-DOAS model is $0.0134(1.3 \%)$.

The fit residuals, i.e. the difference spectra between measurement and model as shown in Fig. 5 are not yet signalto-noise limited but are dominated by rather stable spectral artifacts. This needs further investigation, e.g. by analysing time series, but is most probably due to a combination of various errors such as errors in the spectroscopic data (Rothman et al., 2003), errors due to the still preliminary calibration of the SCIAMACHY nadir and solar spectra, and spectrometer slit function uncertainties. Probably as a result of this the $\mathrm{CO}_{2}$ and $\mathrm{O}_{2}$ columns initially retrieved showed a significant bias, namely a systematic underestimation of the $\mathrm{CO}_{2}$ columns and an overestimation of the $\mathrm{O}_{2}$ columns (the mixing ratios of these gases are quite well known and do not vary very much; therefore a good estimate of their columns for a given location can be made even without any SCIAMACHY measurement). In order to roughly compensate for this, constant (i.e. space and time independent) scaling factors have been applied to all WFM-DOAS version $0.4 \mathrm{CO}_{2}$ and $\mathrm{O}_{2}$ columns shown in this study. These scaling factors are 1.27 for the $\mathrm{CO}_{2}$ columns and 0.85 for the $\mathrm{O}_{2}$ columns. All columns have simply been multiplied with these factor (this transformation can be reversed, if considered necessary, by dividing all WFM-DOAS version 0.4 columns by these numbers). As absolute measurements are difficult, scaling factors have also been used in other studies. For example, Yang et al. (2002) applied a scaling factor of 1.058 to their $\mathrm{XCO}_{2}$ measurements. The WFM-DOAS version $0.4 \mathrm{CH}_{4}$ columns have not been scaled. This issue needs further study and we hope that in the future we do not need the scaling factors any more. At this point we focus on finding out to what extent atmospheric variability can be detected with SCIAMACHY because this is where the information on sources and sinks mainly comes from.

\section{Global models of chemistry and transport}

In this section a short description the global models of chemistry and transport used in the study is given. Three different models have been used, two for the methane comparison (TM3 model of KNMI, TM5 model of JRC) and one for the comparison of carbon dioxide (TM3 model of MPI-BGC).

\subsection{TM3 model of KNMI}

TM3 is a global off-line chemistry-transport model driven by meteorological fields from the ECMWF weather forecast model. The model is run on a resolution of $2.5 \times 2.5^{\circ}$ and 31 vertical layers. The version applied here is basically the same as described in Lelieveld and Dentener (2000), except that $\mathrm{CH}_{4}$ emissions are included, closely following Houweling et al. (1999). $\mathrm{CH}_{4}$ concentrations at the highest model level $(10 \mathrm{hPa})$ are nudged to the monthly-mean zonal HALOE/CLAES climatology from UARS. 

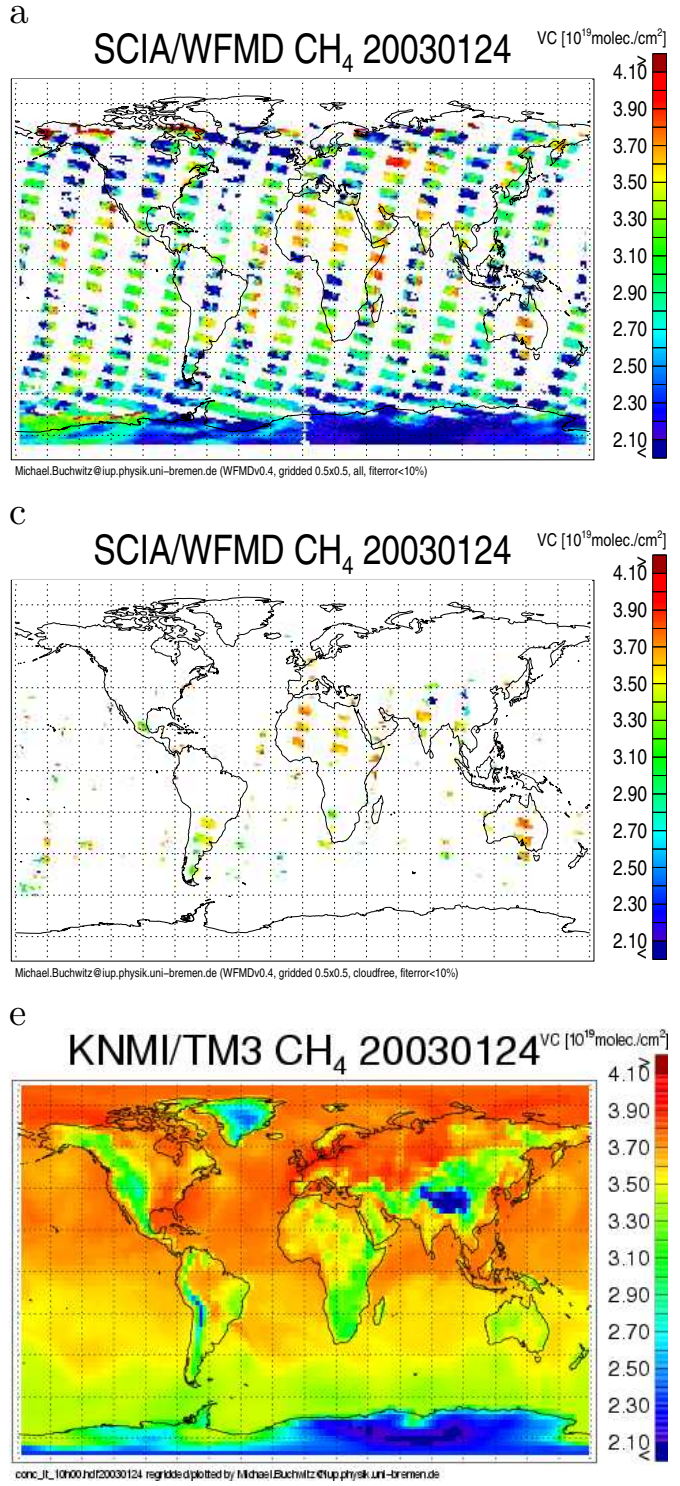

$\mathrm{b}$

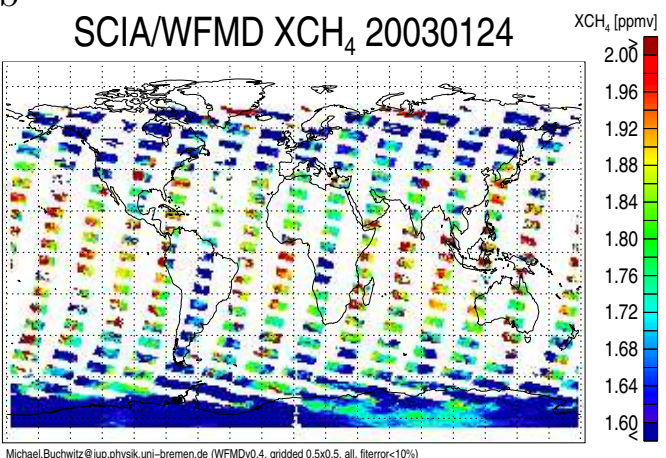

d

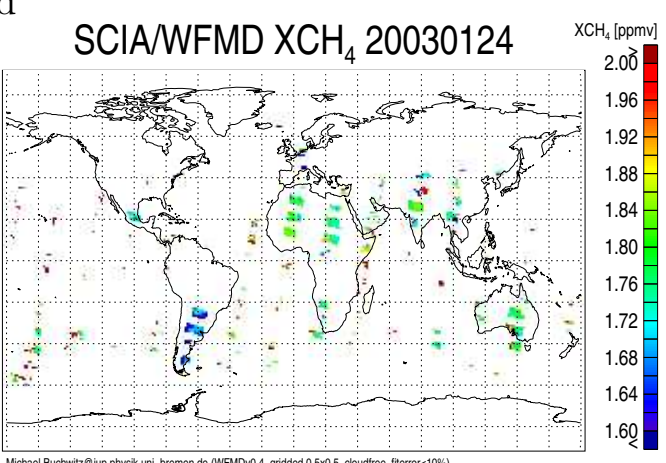

f

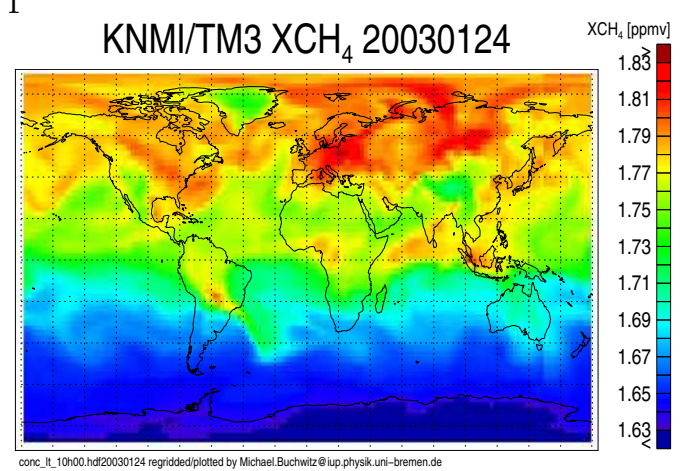

Fig. 6. Panel (a): Methane vertical columns (VC) on 24 January 2003, as retrieved from SCIAMACHY. Shown are all data with fit errors less than 10\%. (b): As (a) but for $\mathrm{XCH}_{4}$. Panels (c) and (d): As (a) and (b) but restricted to cloud free pixels. (e): Methane vertical columns from KNMI/TM3 model. (f): $\mathrm{XCH}_{4}$ from KNMI/TM3 model.

\subsection{TM5 model of JRC}

The TM5 model is a two-way nested atmospheric zoom model (Krol et al., 2005). It allows to define zoom regions (e.g. over Europe) which are run at higher spatial resolution $\left(1 \times 1^{\circ}\right)$, embedded into the global domain, run at a resolution of $6 \times 4^{\circ}$. We employ the tropospheric standard version of TM5 with 25 vertical layers. TM5 is an off-line model and uses analysed meteorological fields from the ECMWF weather forecast model to describe advection and vertical mixing by cumulus convection and turbulent diffusion. $\mathrm{CH}_{4}$ emissions are as described by Bergamaschi et al. (2004) (a priori emissions). Chemical destruction of $\mathrm{CH}_{4}$ by $\mathrm{OH}$ rad- icals is simulated using pre-calculated $\mathrm{OH}$ fields based on CBM-4 chemistry and optimised with methyl chloroform, for the stratosphere also the reaction of $\mathrm{CH}_{4}$ with $\mathrm{Cl}$ and $\mathrm{O}\left({ }^{1} \mathrm{D}\right)$ radicals are considered.

\subsection{TM3 model of MPI-BGC}

TM3 3.8 (Heimann and Körner, 2003) is a three-dimensional global atmospheric transport model for an arbitrary number of active or passive tracers. It uses re-analysed meteorological fields from the National Centre for Environmental Prediction (NCEP) or from the ECMWF re-analysis. The modelled processes comprise tracer advection, vertical transport due 
to convective clouds and turbulent vertical transport by diffusion. Available horizontal resolutions range from $8 \times 10^{\circ}$ to $1.1 \times 1.1^{\circ}$. In this case, TM3 was run with a resolution of $1.8 \times 1.8^{\circ}$ and 28 layers, and the meteorology fields were derived from the NCEP/DOE AMIP-II reanalysis. $\mathrm{CO}_{2}$ source/sink fields for the oceans originate from Takahashi et al. (2002), for anthropogenic emissions from the EDGAR 3.2 database and for the biosphere from the BIOME-BGC model.

Since the finalisation of the first version of TM3 in 1993 the model has been used in numerous simulations of greenhouse-gas related effects. After model enhancements, transport properties were always verified (Heimann and Körner, 2003). Concerning $\mathrm{CO}_{2}$, a careful evaluation of TM3 results with in situ atmospheric measurements from various air-craft campaigns and ground based measurements shows that the model simulates realistic mixing ratio distributions at the surface but also in upper parts of the troposphere (Peylin et al., personal communication ${ }^{1}$ ).

The TM3 model output contains 3-dimensional timeseries of average $\mathrm{CO}_{2}$ mixing ratios per grid box. To get the column abundance in molecules $/ \mathrm{cm}^{2}$, those values are multiplied with the air mass of the respective boxes, summed-up in the vertical and divided by the area. Column averaged mixing ratios were computed by dividing the column abundance by the respective column air mass.

\section{Comparison of SCIAMACHY data with models}

In order to facilitate a quantitative comparison of the SCIAMACHY data with the model fields, all data have been gridded on a common $0.5 \times 0.5^{\circ}$ latitude/longitude grid. This corresponds to a grid box size of about $50 \times 50 \mathrm{~km}^{2}$ (except at high latitudes) which is on the order of the resolution of the SCIAMACHY ground pixels $\left(\mathrm{CO}_{2}: 30 \times 60 \mathrm{~km}^{2}, \mathrm{CH}_{4}\right.$ : $30 \times 120 \mathrm{~km}^{2}$ ). The model grids are typically integer multiples of $0.5^{\circ}$. This enables to map the model data onto the $0.5^{\circ}$ grid without any interpolation. The only exception is the MPI-BGC/TM3 model where a bi-linear interpolation scheme has been used.

\subsection{Methane columns and $\mathrm{XCH}_{4}$}

In this section SCIAMACHY data are compared with corresponding model data. Detailed results are presented for four days of the year 2003 (24 January, 28 March, 30 May, and 23 July). These days have been selected based on several criteria with the main criterion being availability of all 14 daily ENVISAT orbits in consolidated Level $1 \mathrm{~b}$ format (i.e. entire orbits including all the necessary auxiliary data needed for calibration). Not all ENVISAT orbits have yet been processed and made available by ESA and only for a

\footnotetext{
${ }^{1}$ P. Peylin, personal communication, Laboratoire des Sciences du Climat et l'Environement, Gif-sur-Yvette, France
}

small number of days all 14 daily orbits were available for this study.

Figure 6a shows the methane vertical columns as retrieved from the SCIAMACHY measurements from 24 January 2003. As described above, no cloud correction is being performed by WFM-DOAS. The low columns (shown in blue) mainly correspond to cloud covered scenes for which only the column above the cloud is observed. This can be seen by comparing (the blue regions of) Fig. 6a with (the white regions of) Fig. 3. Only ground pixels with a methane column fit error of less than $10 \%$ are shown in Fig. 6a, i.e. only pixels where a relatively good match of the WFM-DOAS model and the measurements has been achieved. Most of the rejected pixels (those having a fit error larger than 10\%) are located over the oceans. Except for sun-glint conditions the reflectivity of the ocean is low, especially at nearinfrared wavelength. As a result, the signal detected by SCIAMACHY is low and, therefore, also the signal-to-noise ratio, resulting in spectral fits being significantly worse compared to fits over land.

Figure $6 \mathrm{c}$ shows the same columns as shown in Fig. 6a but restricted to cloud free pixels. These columns can be compared with the corresponding KNMI/TM3 model columns shown in Fig. 6e. As can be seen, the measured columns correspond quite well with the model columns. The lowest columns (blue) are located over elevated regions, e.g., the Himalaya region. Column variations are primarily due to changes of surface topography (the higher the average surface elevation of a ground pixels the lower the air mass above this pixel and the lower the column of a well-mixed gas). Over northern Africa the measured as well as the model columns are in the range $3.5-3.8 \times 10^{19}$ molecules $/ \mathrm{cm}^{2}$. Over South America the columns are significantly lower (less than $3.4 \times 10^{19}$ molecules $/ \mathrm{cm}^{2}$ ), especially over the Andes mountains. This is true for the measurements as well as for the model data. Over Australia the measured columns are around $3.7 \times 10^{19}$ molecules $/ \mathrm{cm}^{2}$ which is a few percent higher than the model columns which are around $3.5 \times 10^{19}$ molecules $/ \mathrm{cm}^{2}$.

Figure $6 \mathrm{~b}$ shows the methane dry air column averaged mixing ratio $\mathrm{XCH}_{4}$ as measured by SCIAMACHY for all ground pixels where the methane fit error is less than $10 \%$. Figure $6 \mathrm{~d}$ shows the same data but restricted to the cloud free pixels. Figure 6f shows the corresponding KNMI/TM3 model results. The colour scale used for Fig. $6 \mathrm{f}$ is not exactly identical with the colour scale used for Fig. $6 \mathrm{~d}$ in order to better show the $\mathrm{XCH}_{4}$ spatial pattern, which is somewhat "smoother" in the model compared to the measurements. Figure 6 enables a comparison of the measured and the modelled $\mathrm{XCH}_{4}$. Overall, the patterns agree quite well. Both data sets show relatively high values in the northern hemisphere and relatively low values over South America. Over Australia the measured $\mathrm{XCH}_{4}$ is about $1-2 \%$ higher $(\sim 1.74 \mathrm{ppmv})$ compared to the model $(\sim 1.70 \mathrm{ppmv})$. Differences on the order of $1-2 \%$ are also observed over other 

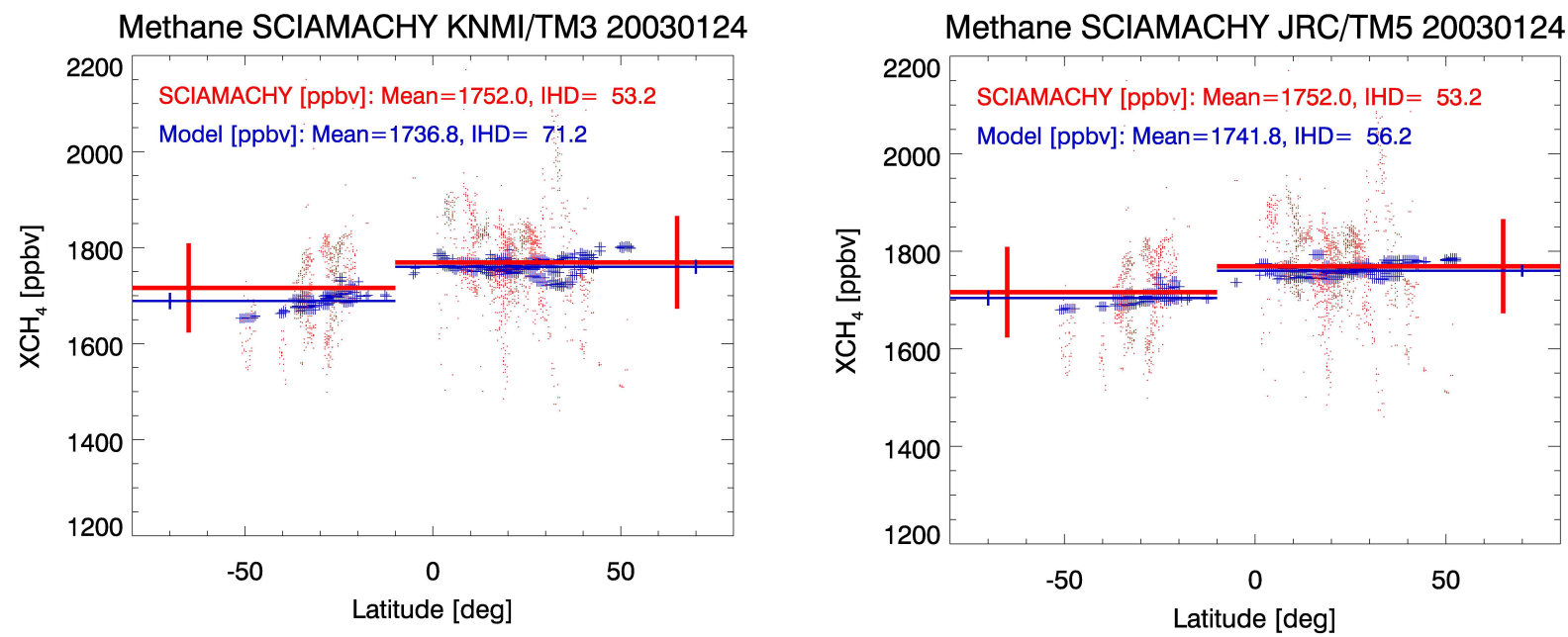

Fig. 7. $\mathrm{XCH}_{4}$ as a function of latitude as measured by SCIAMACHY (red points) and the corresponding KNMI/TM3 (left) and JRC/TM5 (right) model data (blue crosses). The two horizontal red lines show the average values of the SCIAMACHY data in the latitude bands -90 to $-10^{\circ}$ and -10 to $+90^{\circ}$. The two vertical red lines indicate the standard deviation of the SCIAMACHY data in the two latitude bands. The blue lines show the same quantities but for the models. The comparison is limited to cloud free measurements over land. The mean value of all the SCIAMACHY data is $1752.0 \mathrm{ppbv}$ and the corresponding model values are $1736.8 \mathrm{ppbv}$ (KNMI/TM3) and 1741.8 ppbv (JRC/TM5). The interhemispheric difference (IHD) as measured by SCIAMACHY is 53.2 ppbv and the corresponding model values are 71.2 ppbv (KNMI/TM3) and 56.2 ppbv (JRC/TM5).

regions, e.g. over Mexico, where the measured $\mathrm{XCH}_{4}$ is $\sim 1.72$ ppmv and the model values are around $\sim 1.76 \mathrm{ppmv}$. The largest difference is observed over the Himalaya region, where the measured $\mathrm{XCH}_{4}$ are about $10 \%$ higher than the model values.

Figure 7 shows the measured $\mathrm{XCH}_{4}$ and the KNMI/TM3 and JRC/TM5 model values as a function of latitude. As can be seen, the variability of the measured $\mathrm{XCH}_{4}$ is significantly higher $(\sim 100 \mathrm{ppbv}$ or $5 \%)$ than the model $\mathrm{XCH}_{4}$ ( $\sim 30 \mathrm{ppbv})$. The hemispheric averages of the SCIAMACHY data (red horizontal lines) agree quite well with the corresponding model values which have been computed using the same (latitude/longitude) grid boxes as used for SCIAMACHY. The difference between the hemispheric averages is the inter-hemispheric difference (IHD). The IHD as determined from the SCIAMACHY measurements on 24 January 2003, is $53 \mathrm{ppbv}$. The corresponding model values are $71 \mathrm{ppbv}$ for the KNMI/TM3 model and $56 \mathrm{ppbv}$ for the JRC/TM5 model. Note that the model values have been determined taking into account the spatial sampling of SCIAMACHY and, therefore, are not identical with a model IHD computed from all model grid boxes. For this day a latitude of $10^{\circ}$ south has been selected to "separate" the hemispheres. This latitude roughly corresponds to the (average) position of the inter-tropical convergence zone (ITCZ) in January as can be concluded from, e.g. Fig. 7, which shows a gap of SCIAMACHY measurements around $-10^{\circ}$ latitude due to large cloud cover (typical for the ITCZ) with higher than average methane mixing ratios north of this region and lower mixing ratios south of this latitude. Both models use the same meteorology (ECMWF), advection scheme and parameterisation of sub-grid-scale vertical mixing. However, they are applied here in different resolutions (TM3: $2.5 \times 2.5$; TM5: $6 \times 4$, over Europe $1 \times 1$ ) and use different $\mathrm{CH}_{4}$ emission inventories. A coupled European-global inversion based on the TM5 model has recently been performed by Bergamaschi et al. (2004), using high-precision ground-based in-situ measurements. The inversion, performed for year 2001, suggests e.g. higher emission from USA, Southern Africa, and India, and lower emission from Northern Africa, Russia and East Asia compared to the bottom-up inventory used in this study, with significant influence on the simulated global $\mathrm{CH}_{4}$ distribution. For future comparisons of SCIAMACHY data we will use such optimised $\mathrm{CH}_{4}$ simulations, representing a calibrated reference consistent with global in-situ observations.

A similar analysis has also been performed for three other days of the year 2003. The results are summarised in Tables 2 and 3 . These tables shows that the quantities used to characterise the level of similarity between the measurement and the models (i.e. correlation coefficient, mean difference and standard deviation of the difference) are significantly different for the four days analysed. For example the correlation coefficient for the $\mathrm{CH}_{4}$ columns is 0.88 on 24 January 2003, but as low as 0.55 on 30 March 2003. This can be explained, at least partially, by the fact that the correlation coefficient strongly depends on the range of columns observed which is primarily determined by the range of ground pixel surface pressures covered by cloud free pixels (on 24 January, for example, one orbit goes over the nearly cloud free Andes mountains, which is not the case for 30 March). 
Table 2. Overview of the comparison of the $\mathrm{CH}_{4}$ columns as retrieved from SCIAMACHY for cloud free scenes over land for four days with $\mathrm{CH}_{4} \mathrm{KNMI}$ /TM3 model columns. The last column lists the average transmission of SCIAMACHY channel 8 relative to first in-orbit measurements (Source: SCIAMACHY Operations Support Team web page: http://atmos.af.op.dlr.de/projects/scops/).

\begin{tabular}{|c|c|c|c|c|c|c|c|}
\hline Model & Day & $\begin{array}{l}\mathrm{N} \\
\text { grid } \\
\text { boxes }\end{array}$ & $\begin{array}{l}\text { Mean difference } \\
\mathrm{CH}_{4} \text { columns } \\
\text { SCIA-model } \\
\left(10^{19} \text { molec. } / \mathrm{cm}^{2}\right)\end{array}$ & $\begin{array}{l}\text { Standard deviation } \\
\mathrm{CH}_{4} \text { columns } \\
\text { SCIA-model } \\
\left(10^{19} \text { molec. } / \mathrm{cm}^{2}\right)\end{array}$ & $\begin{array}{l}\text { Pearsons r } \\
\mathrm{CH}_{4} \text { columns } \\
\text { SCIA vs. model }\end{array}$ & $\begin{array}{l}\text { Pearsons r } \\
\text { SCIA CH }_{4} \\
\text { vs. } \mathrm{O}_{2} \\
\text { columns }\end{array}$ & $\begin{array}{l}\text { Channel } 8 \\
\text { relative } \\
\text { transmission } \\
(-)\end{array}$ \\
\hline \multirow[t]{4}{*}{ KNMI/TM3 } & $2003 / 01 / 24$ & 2770 & $+0.06(+1.8 \%)$ & $0.18(5.7 \%)$ & 0.88 & 0.87 & 0.9 \\
\hline & $2003 / 03 / 28$ & 4437 & $-0.32(-9.3 \%)$ & $0.21(6.5 \%)$ & 0.82 & 0.89 & 0.7 \\
\hline & $2003 / 05 / 30$ & 7581 & $+0.02(+0.5 \%)$ & $0.38(11.0 \%)$ & 0.55 & 0.84 & 0.8 \\
\hline & $2003 / 07 / 23$ & 8535 & $-0.53(-15.3 \%)$ & $0.32(8.9 \%)$ & 0.62 & 0.86 & 0.6 \\
\hline
\end{tabular}

Table 3. Overview of the comparison of $\mathrm{XCH}_{4}$ as retrieved from SCIAMACHY for cloud free scenes over land for four days with $\mathrm{XCH}_{4}$ KNMI/TM3 and JRC/TM5 model values. The latitudes listed in the table are the latitudes chosen to separate the northern from the southern hemisphere taking into account the position of the inter-tropical convergence zone (ITCZ) for the calculation of the inter-hemispheric difference (IHD) of the column averaged methane mixing ratio $\mathrm{XCH}_{4}$.

\begin{tabular}{|c|c|c|c|c|c|c|c|}
\hline Model & Day & $\begin{array}{l}\text { Mean difference } \\
\mathrm{XCH}_{4} \\
\text { SCIA-model } \\
\text { (ppbv) }\end{array}$ & $\begin{array}{l}\text { Standard deviation } \\
\mathrm{XCH}_{4} \\
\text { SCIA-model } \\
\text { (ppbv) }\end{array}$ & $\begin{array}{l}\text { Pearsons } \mathrm{r} \\
\mathrm{XCH}_{4} \\
\text { SCIA vs. model }\end{array}$ & $\begin{array}{l}\text { Latitude } \\
\text { for IHD } \\
\text { (deg) }\end{array}$ & $\begin{array}{r}\text { IHD } \\
\text { SCIA } \\
(\text { ppbv })\end{array}$ & $\begin{array}{r}\text { IHD } \\
\text { model } \\
(\mathrm{ppbv})\end{array}$ \\
\hline KNMI/ & $2003 / 01 / 24$ & $+15(+0.9 \%)$ & $98(5.7 \%)$ & 0.19 & -10 & 53 & 71 \\
\hline \multirow[t]{3}{*}{ TM3 } & $2003 / 03 / 28$ & $-183(-10.5 \%)$ & $89(5.1 \%)$ & 0.10 & 0 & 30 & 55 \\
\hline & $2003 / 05 / 30$ & $+51(+2.9 \%)$ & $200(11.3 \%)$ & 0.25 & 3 & 110 & 56 \\
\hline & $2003 / 07 / 23$ & $-260(-14.8 \%)$ & $121(6.8 \%)$ & 0.04 & 15 & 31 & 60 \\
\hline $\mathrm{JRC} /$ & $2003 / 01 / 24$ & $+10(+0.6 \%)$ & $97(5.6 \%)$ & 0.18 & -10 & 53 & 56 \\
\hline \multirow[t]{3}{*}{ TM5 } & $2003 / 03 / 28$ & $-186(-10.6 \%)$ & $89(5.1 \%)$ & 0.07 & 0 & 30 & 48 \\
\hline & $2003 / 05 / 30$ & $+48(+2.7 \%)$ & $200(11.3 \%)$ & 0.25 & 3 & 110 & 56 \\
\hline & $2003 / 07 / 23$ & $-266(-15.1 \%)$ & $122(6.8 \%)$ & 0.01 & 15 & 31 & 63 \\
\hline
\end{tabular}

In this context it also has to be pointed out that the WFMDOAS Version 0.4 retrieval scheme and related parameters (degree of the polynomial, slit function parameters, dead and bad detector pixel mask, solar reference spectrum, etc.) are identical for all days, i.e. the retrieval scheme is rather static. This might not be the optimum because certain time dependencies might need careful consideration, e.g. to take into account effects resulting from the time dependent ice-layer build up in SCIAMACHY's channel 8 (see Sect. 2) which has been used for $\mathrm{CH}_{4}$ retrieval. The average channel 8 relative transmission is shown in the last column of Table 2. This transmission has been determined from ratios of solar (and internal calibration lamp) spectra as measured in-orbit by SCIAMACHY. The transmission values listed characterise the change of the transmission relative to the first in-orbit measurements. In order to bring this transmission back to its maximum value (of $\sim 1.0$ ) SCIAMACHY (more precisely, its radiant cooler) is regularly heated ("decontamination") to get rid of the ice layer. After decontamination the transmission is close to 1.0 but decreases (roughly exponentially) with time. Table 2 shows that the transmission is highest (0.9) for 24 January 2003. For this day (a day shortly after a major decontamination phase) the comparison with the KNMI/TM3 model shows the best agreement (e.g. highest correlation coefficient, smallest standard deviation of the difference). For 28 March and 23 July the SCIAMACHY $\mathrm{CH}_{4}$ columns are on average $10-15 \%$ lower than the model columns (whereas for the other days the agreement is within 2\%). For these two days the transmission has its lowest value. The tables show that the level of agreement (measured by, e.g. the mean difference) between measurement and model(s) is similar for $\mathrm{CH}_{4}$ and $\mathrm{XCH}_{4}$. This shows that the time dependence of the quality of the retrieval is primarily determined by the channel 8 methane column retrieval and not by the channel $4 \mathrm{O}_{2}$ retrieval (as the division by $\mathrm{O}_{2}$ performed to obtain $\mathrm{XCH}_{4}$ does not change the time dependence). This time dependence needs further investigation by careful analysis of more data (e.g. using an entire year) which is beyond the scope of the 
Table 4. Overview of the comparison of the $\mathrm{O}_{2}$ columns as retrieved from SCIAMACHY for cloud free scenes over land for four days with $\mathrm{O}_{2}$ columns computed from ECMWF surface pressure $\left(\mathrm{p}_{s}\right)$. The conversion has been done assuming that a surface pressure of $1013 \mathrm{hPa}$ corresponds to an $\mathrm{O}_{2}$ column of $4.51 \times 10^{24}$ molecules $/ \mathrm{cm}^{2}$.

\begin{tabular}{|c|c|c|c|c|}
\hline Model & Day & $\begin{array}{l}\text { Mean difference } \\
\mathrm{O}_{2} \text { columns } \\
\text { SCIA-model } \\
\left(10^{24} \text { molec. } / \mathrm{cm}^{2}\right)\end{array}$ & $\begin{array}{l}\text { Standard deviation } \\
\mathrm{O}_{2} \text { columns } \\
\text { SCIA-model } \\
\left(10^{24} \text { molec. } / \mathrm{cm}^{2}\right)\end{array}$ & $\begin{array}{l}\text { Pearsons } \mathrm{r} \\
\mathrm{O}_{2} \text { columns } \\
\text { SCIA vs. model }\end{array}$ \\
\hline ECMWF/KNMI & $\begin{array}{l}2003 / 01 / 24 \\
2003 / 03 / 28 \\
2003 / 05 / 30 \\
2003 / 07 / 23\end{array}$ & $\begin{array}{l}+0.00(+0.2 \%) \\
+0.02(+0.7 \%) \\
-0.10(-2.1 \%) \\
-0.07(-1.7 \%)\end{array}$ & $\begin{array}{l}0.30(7.9 \%) \\
0.32(8.3 \%) \\
0.51(12.0 \%) \\
0.46(10.8 \%)\end{array}$ & $\begin{array}{l}0.62 \\
0.59 \\
0.27 \\
0.38\end{array}$ \\
\hline
\end{tabular}

Table 5. Overview of the comparison of the $\mathrm{CO}_{2}$ columns as retrieved from SCIAMACHY for cloud free scenes over land for four days with $\mathrm{CO}_{2}$ MPI-BGC/TM3 model columns.

\begin{tabular}{lllllll}
\hline Model & Day & $\begin{array}{l}\mathrm{N} \\
\text { grid } \\
\text { boxes }\end{array}$ & $\begin{array}{l}\text { Mean difference } \\
\mathrm{CO}_{2} \text { columns } \\
\left.\mathrm{SCIA-model}_{\left(10^{21} \text { molec./cm }\right.}{ }^{2}\right)\end{array}$ & $\begin{array}{l}\text { Standard deviation } \\
\mathrm{CO}_{2} \text { columns } \\
\text { SCIA-model } \\
\left(10^{21} \text { molecules/cm }\right.\end{array}$ & $\begin{array}{l}\text { Pearsons } \mathrm{r} \\
\mathrm{CO}_{2} \text { columns } \\
\mathrm{SCIA} \text { vs. model }\end{array}$ & $\begin{array}{l}\text { Pearsons } \mathrm{r} \\
\mathrm{SCIA} \mathrm{CO}_{2} \\
\text { vs. } \mathrm{O}_{2} \\
\text { columns }\end{array}$ \\
\hline MPI-BGC/TM3 & $2003 / 01 / 24$ & 2990 & $+0.14(+2.0 \%)$ & $0.50(7.6 \%)$ & 0.65 & 0.89 \\
& $2003 / 03 / 28$ & 4206 & $+0.06(0.9 \%)$ & $0.54(7.9 \%)$ & 0.66 & 0.89 \\
& $2003 / 05 / 30$ & 6982 & $-0.18(-2.3 \%)$ & $0.83(11.4 \%)$ & 0.34 & 0.83 \\
& $2003 / 07 / 23$ & 9051 & $-0.27(-3.7 \%)$ & $0.82(11.2 \%)$ & 0.35 & 0.88 \\
\hline
\end{tabular}

Table 6. Overview of the comparison of $\mathrm{XCO}_{2}$ as retrieved from SCIAMACHY for cloud free scenes over land for four days with $\mathrm{XCO}_{2}$ MPI-BGC/TM3 model values. The latitudes listed in the table are the latitudes chosen to separate the northern from the southern hemisphere taking into account the position of the inter-tropical convergence zone (ITCZ) for the calculation of the inter-hemispheric difference (IHD) of the column averaged $\mathrm{CO}_{2}$ mixing ratio $\mathrm{XCO}_{2}$. Positive (negative) values of the IHD indicate larger mixing ratios over the northern (southern) hemisphere.

\begin{tabular}{lllllrrr}
\hline Model & Day & $\begin{array}{l}\text { Mean difference } \\
\mathrm{XCO}_{2} \\
\text { SCIA-model } \\
(\mathrm{ppmv})\end{array}$ & $\begin{array}{l}\text { Standard deviation } \\
\mathrm{XCO}_{2} \\
\text { SCIA-model } \\
(\mathrm{ppmv})\end{array}$ & $\begin{array}{l}\text { Pearsons } \mathrm{r} \\
\mathrm{XCO}_{2} \\
\text { SCIA vs. model }\end{array}$ & $\begin{array}{r}\text { Latitude } \\
\text { for IHD } \\
(\mathrm{deg})\end{array}$ & $\begin{array}{r}\text { IHD } \\
\text { SCIA } \\
(\mathrm{ppmv})\end{array}$ & $\begin{array}{r}\text { IHD } \\
\text { model } \\
(\mathrm{ppm})\end{array}$ \\
\hline MPI-BGC/ & $2003 / 01 / 24$ & $-5.1(-1.4 \%)$ & $14.4(3.9 \%)$ & 0.11 & -10 & +4.4 & +3.0 \\
TM3 & $2003 / 03 / 28$ & $-10.6(-2.8 \%)$ & $16.7(4.5 \%)$ & 0.26 & 0 & +11.7 & +5.1 \\
& $2003 / 05 / 30$ & $-10.9(-2.9 \%)$ & $32.1(8.5 \%)$ & 0.11 & 3 & +10.3 & +3.1 \\
& $2003 / 07 / 23$ & $-18.8(-5.1 \%)$ & $20.2(5.4 \%)$ & 0.25 & 15 & -10.4 & -1.4 \\
\hline
\end{tabular}

current study (our recent analysis of nearly a year of data has confirmed that there is in fact a very clear correlation between the methane bias and the throughput loss of channel 8). Also its consequences for future versions of WFM-DOAS need to be assessed. Table 2 shows that $N$, the number of (latitude/longitude) grid boxes is significantly different for the four days investigated. This is mainly due to a significantly larger number of cloud free pixels over land for the northern hemisphere when going from northern hemisphere winter to northern hemisphere summer (see Fig. $6 \mathrm{~d}$ and the corresponding KNMI/TM3 model data shown in Fig. 6f).

The column averaged mixing ratio of methane has been computed by dividing the retrieved methane column by the retrieved $\mathrm{O}_{2}$ column. Therefore, the quality of the retrieved $\mathrm{O}_{2}$ column is also important. As has been shown in Sect. 4.2 the retrieved $\mathrm{O}_{2}$ columns are not expected to be free of errors. The ECMWF surface pressure as used by the KNMI/TM3 model has been used to compute $\mathrm{O}_{2}$ model columns using the 
$\mathrm{a}$

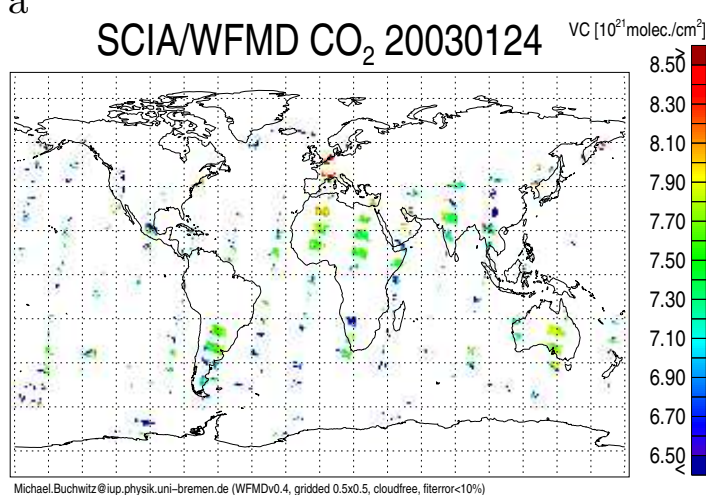

$\mathrm{C}$
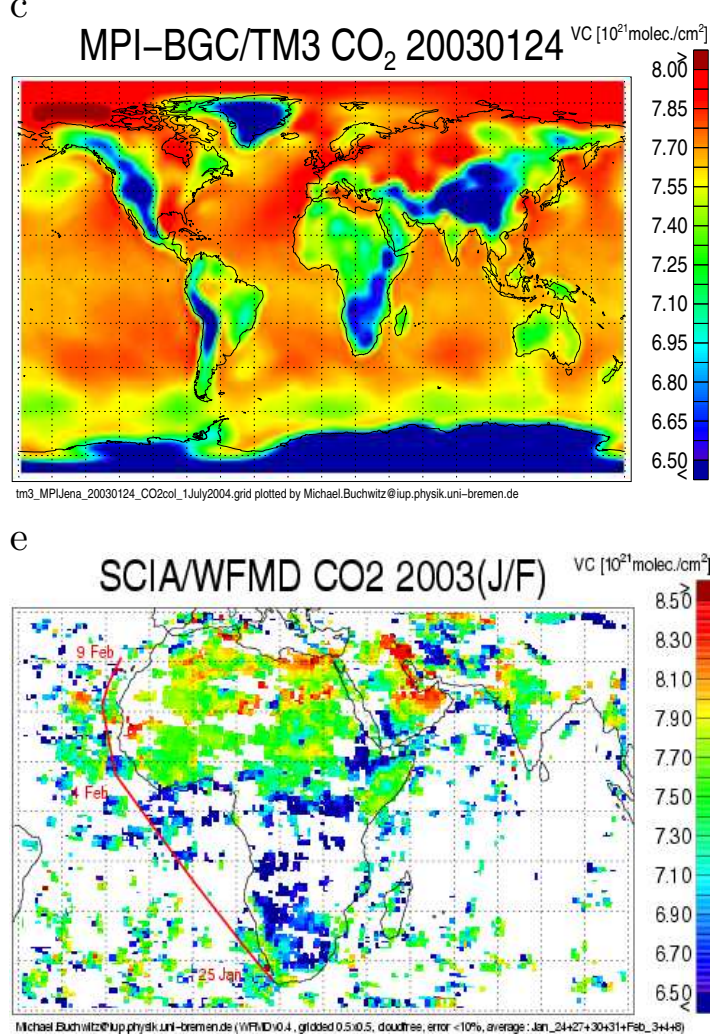

b

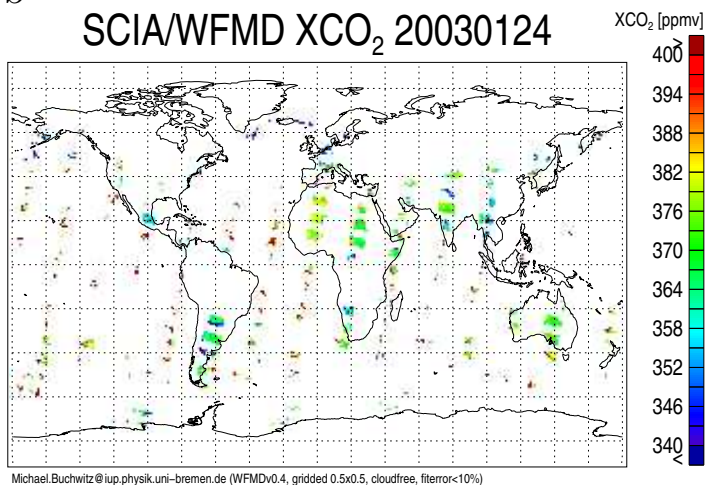

d

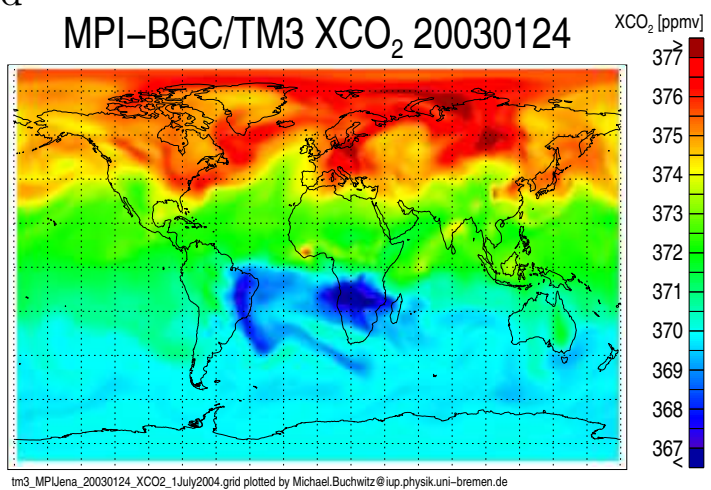

f

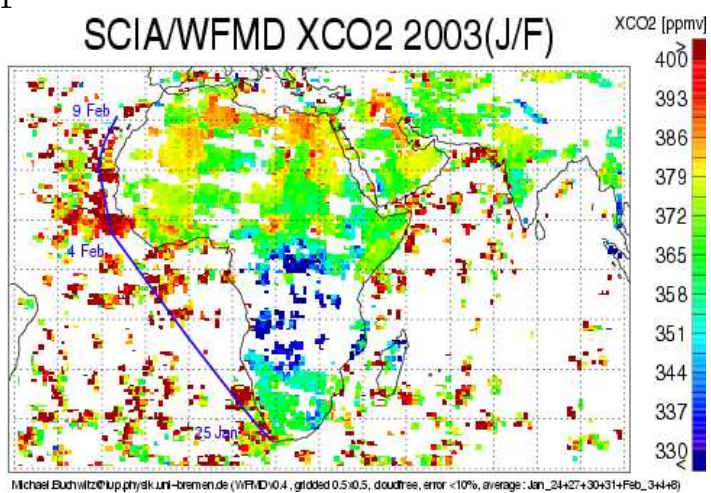

Fig. 8. Panel (a): $\mathrm{CO}_{2}$ columns for cloud free scenes as retrieved from the SCIAMACHY measurements of 24 January 2003. Shown are only the cloud free pixels with a $\mathrm{CO}_{2}$ fit error of less than $10 \%$. Panel (b): As (a) but for $\mathrm{XCO}_{2}$. (c): $\mathrm{CO}_{2}$ vertical columns (VC) on 24 January 2003 from the TM3 model of MPI-BGC. (d): As (c) but for $\mathrm{XCO}_{2}$. Note that the colour scales used for the SCIAMACHY measurements and the TM3 model results are not identical. (e): Similar as panel (a) but average over seven days in the time period end of January to beginning of February 2003. The red lines show the ship track of the research vessel Polarstern (see FTS measurements shown in Fig. 9). Panel (f): As panel (e) but for $\mathrm{XCO}_{2}$.

linear hydrostatic relation between surface pressure and overhead air mass and the constant mixing ratio of $\mathrm{O}_{2}$ in dry air. These $\mathrm{O}_{2}$ model columns have been compared with the $\mathrm{O}_{2}$ columns retrieved from SCIAMACHY. Table 4 summarises the results. As can be seen, the standard deviation of the relative difference is on the same order as for the methane columns (see Table 2). When the $\mathrm{XCH}_{4}$ is computed errors on the individual columns may cancel. This however requires a good correlation between the measured methane and oxygen columns. For the four days investigated in this study the correlation coefficients between the measured $\mathrm{CH}_{4}$ and $\mathrm{O}_{2}$ columns is given in Table 2 showing that the correlation is reasonably good (nearly 0.9 ). 


\subsection{Carbon dioxide columns and $\mathrm{XCO}_{2}$}

In this section SCIAMACHY $\mathrm{CO}_{2}$ measurements are compared with data from the MPI-BGC/TM3 global atmospheric transport model. Figure 8 shows the $\mathrm{CO}_{2}$ columns as retrieved from the SCIAMACHY nadir measurements on 24 January 2003. The columns shown in Fig. 8a are those retrieved from cloud free pixels where at least a reasonable fit of the WFM-DOAS model to the measurements has been achieved (fit error less than $10 \%$, see also Sect. 9.1). Figure $8 \mathrm{c}$ shows the $\mathrm{CO}_{2}$ columns of the MPI-BGC/TM3 model for the same day. The colour scale is different for both figures. Adjusting the colour scale was necessary in order to better visualise the spatial column distributions in the two data sets. As can be seen, the spatial pattern are quite similar: both data sets show low columns over the Himalaya, the Andes and over south Africa and larger columns over north Africa and Australia. The linear correlation coefficient (Pearsons $r$ ) is 0.65 , the mean difference is $0.14 \times 10^{21}$ molecules $/ \mathrm{cm}^{2}(2 \%)$, and the standard deviation of the difference is $\pm 0.50 \times 10^{21}$ molecules $/ \mathrm{cm}^{2}(7.6 \%)$. Figures $8 \mathrm{~b}$ and $8 \mathrm{~d}$ show the corresponding $\mathrm{CO}_{2}$ dry air column averaged mixing ratios $\mathrm{XCO}_{2}$. The standard deviation of the difference is \pm 14.4 ppmv (3.9\%) for the data over land.

The quantitative results of this comparison, also for the three other days discussed in this paper, are summarised in Tables 5 and 6. For the $\mathrm{CO}_{2}$ columns and for $\mathrm{XCO}_{2}$ the bias relative to the model is about a few percent for all four days. The standard deviation of the difference is in the range 7$12 \%$ for the $\mathrm{CO}_{2}$ columns and about a factor of two better for $\mathrm{XCO}_{2}$ which indicates that errors cancel when the retrieved $\mathrm{CO}_{2}$ column is divided by the retrieved $\mathrm{O}_{2}$ column (for the quality of the retrieved $\mathrm{O}_{2}$ columns see Table 4). The correlation coefficients between the measured $\mathrm{CO}_{2}$ columns and the measured $\mathrm{O}_{2}$ columns is nearly 0.9 (see Table 5). Table 6 also lists the inter-hemispheric differences (IHD) of the $\mathrm{CO}_{2}$ mixing ratio as measured by SCIAMACHY compared to the corresponding model values. This comparison shows that SCIAMACHY can detect the small inter-hemispheric difference with single day data. The magnitude of the measured difference is, however, systematically larger than the corresponding model values.

A prominent feature of the model results shown in Fig. 8d is an extended region of relatively low $\mathrm{CO}_{2}$ mixing ratios in the southern part of Africa around Zambia. Here the mixing ratio is about 5 ppmv lower than typical values in the surroundings. The meteorology over southern Africa is dominated by a persistent high pressure system causing a largescale, counterclockwise rotating closed circulation system. This acts as a giant containment reservoir for trace gases. The African tropical/sub-tropical regional sink in the model is primarily due to $\mathrm{CO}_{2}$ uptake by vegetation in their main growing season. According to the model, this sink converts into a relatively strong source six months later, when the drought season begins.

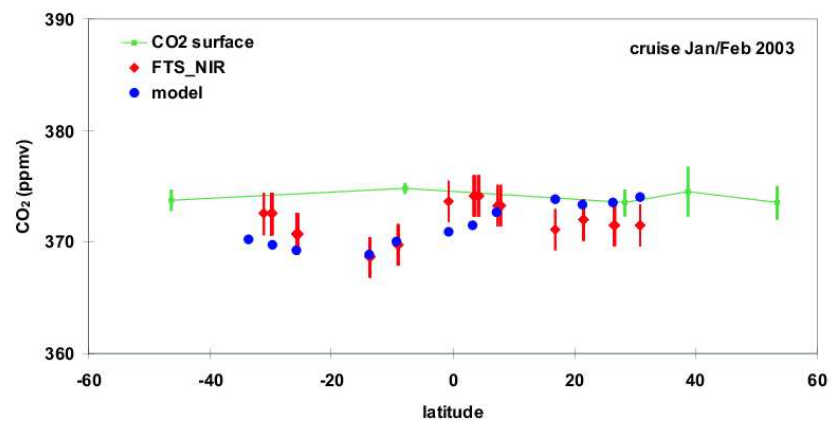

Fig. 9. Column averaged $\mathrm{CO}_{2}$ mixing ratios (red) measured by Fourier Transform Spectroscopy (FTS) during a ship cruise on the Atlantic in January/February 2003. The ship track is shown in Fig. 8e. The corresponding MPI-BGC/TM3 $\mathrm{XCO}_{2}$ model data are shown in blue. In-situ surface sampling data performed by NOAA/CMDL at ground stations close to the cruise track are shown as green symbols (connected by a green line). The surface stations are: Mace Head, Terceira Island, Tenerife Island, Ascension, and Crozet Island. The green vertical bars indicate the variation of surface $\mathrm{CO}_{2}$ mixing ratio over the time of the cruise at each station.

Unfortunately, due to clouds, this apparently interesting region is not observed in the SCIAMACHY data on 24 January 2003 (see Fig. 8b). In order to increase the number of cloud free pixels in this area all available orbits (for seven days of SCIAMACHY data) from in the time period 24 January to 8 February 2003, have been processed. The results have been averaged (using only the cloud free pixels with a fit error less than 10\%) and these averages are shown in Figs. 8e and $8 \mathrm{f}$ ). As can be seen, the spatial distribution of the $\mathrm{CO}_{2}$ columns and mixing ratios as measured by SCIAMACHY over Africa show good agreement with the corresponding model data. The SCIAMACHY measurements show an extended region of low $\mathrm{CO}_{2}$ mixing ratios over a similar region than the model. The measured $\mathrm{CO}_{2}$ mixing ratios in the Zambia/Congo area are about $20 \mathrm{ppmv}$ lower than typical values in its surroundings, whereas the depth of the $\mathrm{CO}_{2}$ trough in the model is about 5 ppmv.

According to the model the air masses with the low $\mathrm{CO}_{2}$ concentrations over Zambia are transported by winds westward over the Atlantic ocean where the mixing ratios in the latitude range $5^{\circ} \mathrm{S}-25^{\circ} \mathrm{S}$ are several ppmv lower than the background concentration (see Figs. 8d). These air masses have been observed by ship-based solar occultation Fourier Transform Spectroscopy (FTS) measurements obtained in the same time period during a cruise of the German research vessel Polarstern (Warneke et al., 2005). As shown in Fig. 9 the column averaged $\mathrm{CO}_{2}$ mixing ratios measured by FTS in the latitude range $5^{\circ} \mathrm{S}-25^{\circ} \mathrm{S}$ are up to 5 ppmv lower than the background concentrations observed at higher and lower latitudes. This is roughly consistent with the model simulations. Figure 9 also shows that these extremely low $\mathrm{CO}_{2}$ mixing ratios are not observed by the network of ground stations, 

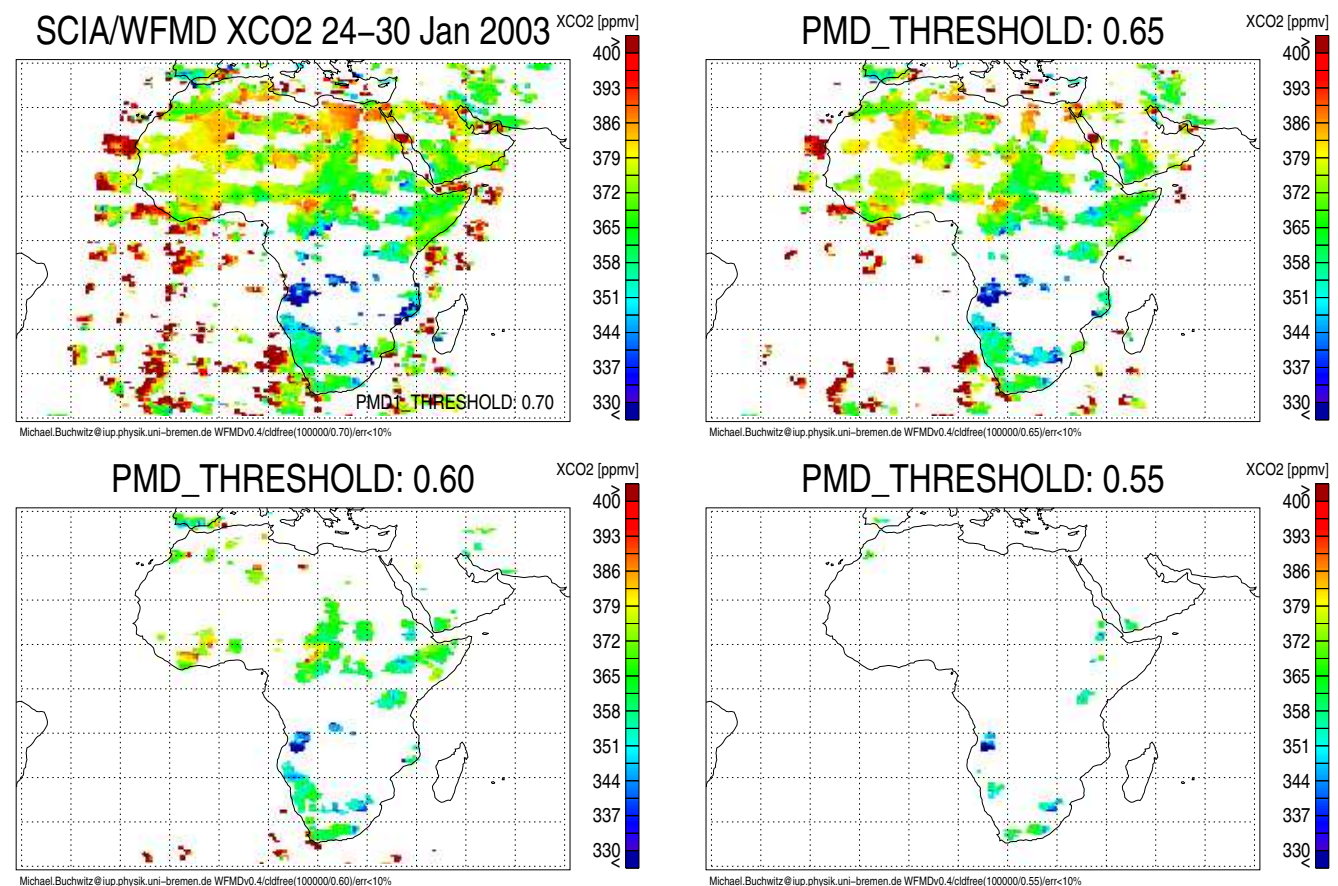

Fig. 10. The column averaged mixing ratio of $\mathrm{CO}_{2}$ as measured by SCIAMACHY as a function of the PMD1 threshold used to identify cloud free scenes. Top left: As Fig. 8f but restricted to 16 ENVISAT orbits passing over Africa in the time period 24-30 January 2003. The WFM-DOAS v0.4 default value of 0.7 for the PMD1 threshold has been used to identify cloud free pixels. The PMD1 readouts are divided by the cosine of the solar zenith angle and a pre-defined constant value such that (most of) the normalised data are in the range between 0 and 1. PMD sub-pixels with values below 0.7 are classified cloud free. The other three panels also show the average $\mathrm{XCO}_{2}$ but for thresholds of $0.65,0.6$, and 0.55 .

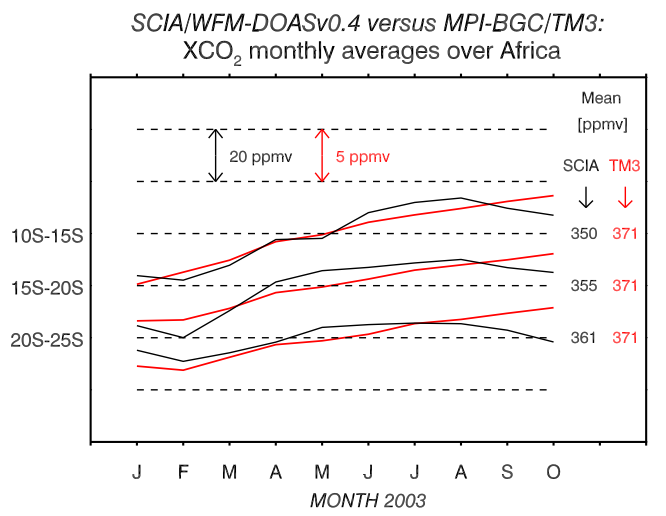

Fig. 11. Monthly mean $\mathrm{XCO}_{2}$ as measured by SCIAMACHY (black lines) determined by averaging data from all available orbits in three $5^{\circ}$ latitude bands over Africa. Only cloud free ground pixels have been considered. The first of the three curves, for example, shows the monthly average $\mathrm{XCO}_{2}$ values for the latitude interval $10^{\circ} \mathrm{S}-15^{\circ} \mathrm{S}$. The average value for this interval is $350 \mathrm{ppmv}$ (see value given on the right hand side). The mixing ratio difference between the dotted horizontal lines is 20 ppmv. From this it can be seen that the $\mathrm{XCO}_{2}$ in the $10^{\circ} \mathrm{S}-15^{\circ} \mathrm{S}$ latitude band is about $(350-18=) 332$ ppmv for February and about $(350+13=) 363$ ppmv for July 2003. The corresponding MPI-BGC/TM3 model data are shown in red. which perform in situ measurements of the $\mathrm{CO}_{2}$ mixing ratio at ground level. The SCIAMACHY measurements have not been included in Fig. 9 because of the low quality of the SCIAMACHY $\mathrm{CO}_{2}$ measurements over ocean (due to the low reflectivity of water in the near-infrared).

In order to investigate the time behaviour of the retrieved $\mathrm{CO}_{2}$ mixing ratios in this region more SCIAMACHY data have been processed. Figure 11 shows monthly averages of the $\mathrm{CO}_{2}$ mixing ratios as measured by SCIAMACHY over Africa in the time period January to October 2003 (no consolidated orbit files for 2003 after October are currently available). The averages have been computed using all the consolidated orbit files that have been made available by ESA for this time period. The data shown are averages for three adjacent $5^{\circ}$ latitude bands. Figure 11 shows that in January/February 2003 the measured mixing ratios are 520 ppmv lower that the January to October 2003 average. Six months later (July/August) the mixing ratios are 5-15 ppmv higher than the average. This time dependence is in reasonable agreement with the model results also shown in Fig. 11. The measured amplitude ( $\sim-20 \mathrm{ppmv})$ is, however, significantly larger than the amplitude of the model data $(\sim 2$ 5 ppmv). The linear trend, which is typically about $1.5 \mathrm{ppmv}$ $\mathrm{CO}_{2}$ increase per year, has not been subtracted from the data shown in Fig. 11. An accurate estimation of this trend from 

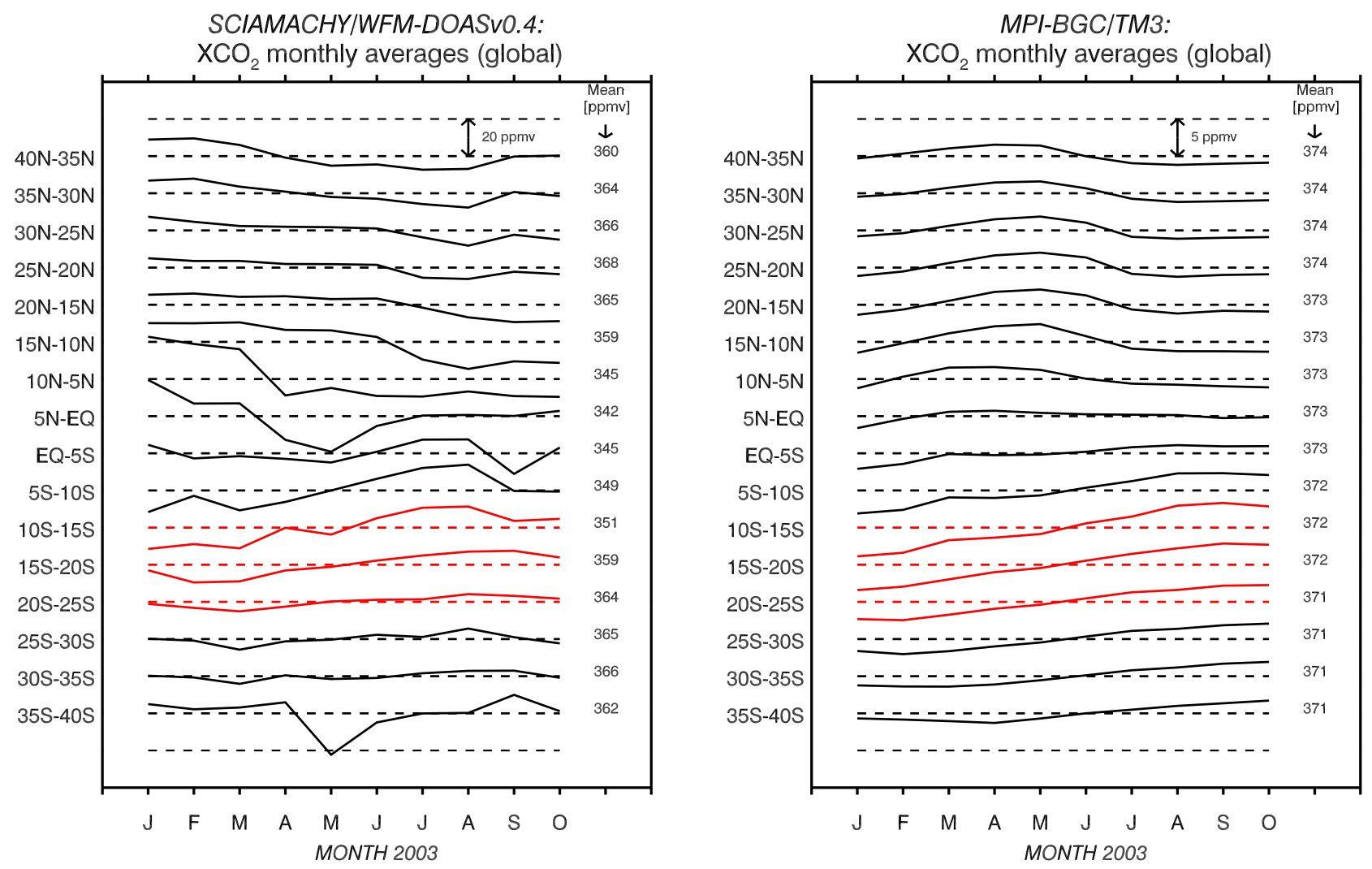

Fig. 12. Panel (a): As Fig. 11 but for global (i.e. not restricted to Africa) year 2003 data over land including an extended range of latitudes. The three latitudes ranges also shown in Fig. 11 are shown in red. The distance between the dashed horizontal lines corresponds to 20 ppmv. The somewhat irregular lines around the equator and at $35-40^{\circ} \mathrm{S}$ are due to the small number of cloud free measurements over land. (b): As (a) but for the MPI-BGC/TM3 model. The averages have been calculated using all model data over land in the corresponding latitude bands. The distance between the dashed horizontal lines corresponds to $5 \mathrm{ppmv}$.

the data requires at least one full seasonal cycle, i.e. one year of data.

For the SCIAMACHY data a significant uncertainty is introduced by the large number of cloud contaminated pixels in the region around Zambia/Congo. Figure $8 \mathrm{f}$ shows large gaps indicating no cloud free pixels even in the several days average. The $\mathrm{XCO}_{2}$ values observed for the cloud free pixels located in between the clouds are, however, consistent. They are consistently lower than typical values in the surroundings. At present we cannot entirely exclude that the measured trough of (very low) $\mathrm{CO}_{2}$ mixing ratios over the Zambia/Congo area is at least partially due to the shielding effect of clouds not detected by the rather strict cloud identification algorithm used for this study.

In this context it is important to point out that errors on the retrieved (absolute) $\mathrm{CO}_{2}$ columns (resulting from, e.g. clouds) are expected to cancel at least partially when the $\mathrm{CO}_{2}$ mixing ratio is computed due to the division of the retrieved $\mathrm{CO}_{2}$ columns by the simultaneously retrieved $\mathrm{O}_{2}$ columns. This is nicely illustrated in Figs. 8e and $8 \mathrm{f}$ which show that most of the surface pressure induced effects (see, e.g. the extended regions of low $\mathrm{CO}_{2}$ columns over Africa visible in Fig. 8) are not present in the $\mathrm{XCO}_{2}$ field where only a nearly circular region of low mixing ratios in the area around Zambia/Congo is visible.

To investigate if the $\mathrm{XCO}_{2}$ results shown in Fig. $8 \mathrm{f}$ are influenced by clouds, the sensitivity of the $\mathrm{XCO}_{2}$ on the PMD threshold (which is used to identify cloud free pixels) has been investigated. The results are shown in Fig. 10. If the threshold is decreased more and more ground pixels are being classified "cloud contaminated" resulting in larger data gaps. The $\mathrm{XCO}_{2}$ pattern, however, remains basically unchanged. From this one may conclude that the observed " $\mathrm{CO}_{2}$ hole" shown in Fig. 8f is not an artifact resulting from residual cloud contamination.

Figure 12a shows similar results as Fig. 11 but for global data (over land), i.e. not restricted to Africa, and for an extended latitude range. In the latitude range $10^{\circ} \mathrm{S}-25^{\circ} \mathrm{S}$ (shown in red) the seasonal behaviour of the global average is similar as the average over Africa shown in Fig. 11. The amplitude, however, is somewhat lower due to the smoothing introduced by including observations over land areas where 
(according to the model, see Fig. 8f) the column averaged mixing ratios are closer to the background concentration, i.e. where the surface fluxes do not result in large regional mixing ratio variations as over Zambia/Congo. For northern latitudes Fig. 12 shows a similar seasonal behaviour as in the southern hemisphere but with the expected six-months phase shift. Figure $12 \mathrm{~b}$ shows the corresponding results of the MPIBGC/TM3 model. Apart from the different amplitude (which is about a factor of four higher in the SCIAMACHY data) the agreement between measurement and model is good in the latitude range $10^{\circ} \mathrm{S}-25^{\circ} \mathrm{S}$ (shown in red). Outside this latitude band the differences are larger. For example in the northern mid-latitudes the maximum is around April/May in the model data but around February in the SCIAMACHY data.

Figure 12 may be compared with a similarly structured figure from Chedin et al. (2003), where monthly averaged midtropospheric $\mathrm{CO}_{2}$ mixing ratios are shown derived from four years of TOVS/NOAA- 10 data in the latitude range $20^{\circ} \mathrm{S}-$ $20^{\circ} \mathrm{N}$. Figure 2 of Chedin et al. (2003) shows similarities with the results shown in Fig. 12 but also differences. In the latitude range $0^{\circ}-20^{\circ} \mathrm{N}$, for example, the mixing ratios shown in Chedin et al. (2003) are in reasonable agreement with the model data shown in Fig. 12b. The seasonal cycles are similar but the amplitudes are different (e.g., $20^{\circ} \mathrm{N}-$ $15^{\circ} \mathrm{N}$ : Chedin: 3-4 ppmb, MPI-BGC model: 1-2 ppmv). In the latitude range $0^{\circ}-20^{\circ} \mathrm{S}$, however, the mixing ratios shown in Chedin et al. (2003) significantly differ from the mixing ratios shown in Fig. 12. For example, the most pronounced mixing ratio minima are in July-September in Chedin et al. (2003) whereas these are the month where the largest mixing ratios have been measured by SCIAMACHY.

The about a factor of four higher variability of the SCIAMACHY data compared to the model may be explained at least partially by the SCIAMACHY $\mathrm{CO}_{2}$ column averaging kernels (see Fig. 2) which show that $\mathrm{CO}_{2}$ variability is overestimated (by about $50 \%$ ) if the concentration changes are confined to the lowest parts of the troposphere. The SCIAMACHY averaging kernels have not (yet) been applied to the model data when comparing the measurements with the model data. Also the scaling factors used for the $\mathrm{CO}_{2}$ columns (1.27) and the $\mathrm{O}_{2}$ columns $(0.85)$ may contribute to this. They essentially result in a $\mathrm{XCO}_{2}$ scaling factor of 1.49 $(=1.27 / 0.85)$. Both effects together may result in an overestimation of the variability of the measured $\mathrm{XCO}_{2}$ by about a factor of two.

\section{Conclusions}

SCIAMACHY nadir spectra recorded in the time period January to October 2003 have been processed with version 0.4 of the WFM-DOAS inversion algorithm to retrieve vertical columns of $\mathrm{CH}_{4}, \mathrm{CO}_{2}$, and $\mathrm{O}_{2}$. The $\mathrm{O}_{2}$ columns have been used to compute $\mathrm{O}_{2}$ or air normalised greenhouse gas columns, the so called dry air column averaged mixing ratios $\mathrm{XCH}_{4}$ and $\mathrm{XCO}_{2}$. It has been shown that for cloud free measurements over land the SCIAMACHY data are in reasonable agreement with global models of transport and chemistry.

For methane four days have been analysed in detail. The mean differences between the measured and the modelled absolute columns are $+0.5 \%$ and $+1.8 \%$ for two of the analysed days but $-9.3 \%$ and $-15.3 \%$ for the two other days. This indicates that there is a time dependent bias. This bias is most probably related to time dependent instrument characteristics (due to ice build up on the detectors) that have not yet been considered good enough in the calibration and/or retrieval process. The standard deviation of the difference is less than $0.4 \times 10^{19}$ molecules $/ \mathrm{cm}^{2}(\sim 10 \%)$ for all four days. The linear correlation coefficient $r$ is in the range 0.55-0.88. The inter-hemispheric difference of the methane mixing ratio as determined from single day cloud free measurements over land is in the range 30-110 ppbv and in good agreement with the corresponding model data which are in the range 48-71 ppbv.

The WFM-DOAS v0.4 $\mathrm{XCH}_{4}$ data product is not an absolute measurement, as the $\mathrm{O}_{2}$ columns used to normalise the methane columns have been scaled with a constant factor of 0.85 , i.e., $\mathrm{XCH}_{4}$ has essentially been scaled with 1.18 $(=1 / 0.85)$. The WFM-DOAS v0.4 $\mathrm{CO}_{2}$ columns have also been scaled (using a constant scaling factor of 1.27) to compensate for a still to be investigated systematic underestimation. We have used the assumption that the scaling factors are constant, i.e., independent of time and location. If this is a valid assumption down to an accuracy of one or a few percent is currently unclear. Because of the scaling factors this study focused on variability rather than on the absolute values of the methane and $\mathrm{CO}_{2}$ measurements.

The scaled $\mathrm{CO}_{2}$ columns agree with the model data within a few percent. This indicates that there is no obvious time dependent bias (as has been observed for methane). The standard deviation of the difference relative to the model is less than $0.83 \times 10^{21}$ molecules $/ \mathrm{cm}^{2}(\sim 12 \%)$ for all four days. The linear correlation coefficient $r$ is in the range 0.34-0.66. The comparison with the model shows that SCIAMACHY can detect the small (a few ppmv) interhemispheric difference (IHD) of the $\mathrm{CO}_{2}$ mixing ratio using single day measurements. The magnitude of the measured inter-hemispheric difference is systematically larger than the corresponding model IHD. In general, the $\mathrm{CO}_{2}$ variations as measured by SCIAMACHY are about a factor of four larger than the variability of the model data. This can partially be explained by the SCIAMACHY averaging kernels which have not yet been taken into account when comparing the measured data with the model data. Also the currently used scaling factors may contribute to this (because they are larger than 1.0 for the $\mathrm{CO}_{2}$ columns and $\mathrm{XCO}_{2}$ ). The $\mathrm{CO}_{2}$ measurements of SCIAMACHY indicate that for the first time a natural $\mathrm{CO}_{2}$ source/sink region has been detected using satellite measurements. 
Despite the encouraging first results presented here, there is room and need for further improvements. For example, only small spectral windows have been analysed so far covering only a few of the methane and carbon dioxide absorption lines detected by SCIAMACHY. In this context it will be very interesting to retrieve methane (also) from SCIAMACHY channel 6 not affected by a changing ice-layer as channel 8 which has been used for this study. Our ultimate goal is to obtain nearly bias free retrievals with a single measurement precision as close as possible to the theoretical limit of $\sim 1 \%$ (Buchwitz et al., 2000a).

Acknowledgements. We thank G. C. Toon, JPL/NASA, for helpful discussions related to Fig. 1, S. Noël and K. Bramstedt for assistance in pre-processing the SCIAMACHY spectra, and M. Krol for coordination of the TM5 model development. We acknowledge European Commission (EC) 6th Framework Programme (FP) Network of Excellence ACCENT for exchange of useful information and the German computer system Hochleistungsrechner Nord (HLRN). Thanks also to RIVM/TNO (Dutch National Institute for Public Health and the Environment) for their EDGAR 3.2 database (Olivier, 2002), and to $\mathrm{C}$. Le Quéré and $\mathrm{K}$. Trusilova for providing $\mathrm{CO}_{2}$ flux data. NCEP reanalysis 2 data were provided by the NOAA-CIRES Climate Diagnostics Center, Boulder, Colorado, USA, from their web site at http://www.cdc.noaa.gov. Last but not least we would like to thank two anonymous referees for constructive suggestions on how to improve the initial version of this paper. Funding for this study came from the EC (5th FP on Energy, Environment and Sustainable Development, Contract no. EVG1-CT-2002-00079, project EVERGREEN). The University of Bremen contribution has been funded in addition by the German Ministry for Research and Education (BMBF) via DLR-Bonn and GSF/PT-UKF, and by the University and the State of Bremen.

Edited by: D. Lowe

\section{References}

Bergamaschi, P., Krol, M., Dentener, F., Vermeulen, A., Meinhardt, F., Graul, R., Peters, W., and Dlugokencky, E. J.: Inverse modelling of national and European $\mathrm{CH}_{4}$ emissions using the atmospheric zoom model TM5, Atmos. Chem. Phys. Discuss., 5, 1007-1066, 2005,

SRef-ID: 1680-7375/acpd/2005-5-1007.

Bovensmann, H., Burrows, J. P., Buchwitz, M., Frerick, J., Noël, S., Rozanov, V. V., Chance, K. V., and Goede, A.: SCIAMACHY Mission Objectives and Measurement Modes, J. Atmos. Sci., 56, 127-150, 1999

Bovensmann, H., Buchwitz, M., Frerick, J., Hoogeveen, R., Kleipool, Q., Lichtenberg, G., Noël, S., Richter, A., Rozanov, A., Rozanov, V. V., Skupin, J., von Savigny, C., Wuttke, M., and Burrows, J. P.: SCIAMACHY on ENVISAT: In-flight optical performance and first results, in: Remote Sensing of Clouds and the Atmosphere VIII, edited by: Schäfer, K. P., Comèron, A., Carleer, M. R., and Picard, R. H., Proceedings of SPIE, 5235, 160-173, 2004.

Buchwitz, M. and Burrows, J. P.: Retrieval of $\mathrm{CH}_{4}, \mathrm{CO}$, and $\mathrm{CO}_{2}$ total column amounts from SCIAMACHY near-infrared nadir spectra: Retrieval algorithm and first results, in: Remote Sensing of Clouds and the Atmosphere VIII, edited by: Schäfer, K. P., Comèron, A., Carleer, M. R., and Picard, R. H., Proceedings of SPIE, 5235, 375-388, 2004.

Buchwitz, M., Rozanov, V. V., and Burrows, J. P.: A near infrared optimized DOAS method for the fast global retrieval of atmospheric $\mathrm{CH}_{4}, \mathrm{CO}, \mathrm{CO}_{2}, \mathrm{H}_{2} \mathrm{O}$, and $\mathrm{N}_{2} \mathrm{O}$ total column amounts from SCIAMACHY/ENVISAT-1 nadir radiances, J. Geophys. Res., 105, 15 231-15 246, 2000a.

Buchwitz, M., Rozanov, V. V., and Burrows, J. P.: A correlated-k distribution scheme for overlapping gases suitable for retrieval of atmospheric constituents from moderate resolution radiance measurements in the visible/near-infrared spectral region, J. Geophys. Res., 105, 15 247-15 262, 2000 b.

Buchwitz, M., de Beek, R., Bramstedt, K., Noël, S., Bovensmann, H., and Burrows, J. P.: Global carbon monoxide as retrieved from SCIAMACHY by WFM-DOAS, Atmos. Chem. Phys. Discuss., 4, 2805-2837, 2004,

SRef-ID: 1680-7375/acpd/2004-4-2805.

Burrows, J. P., Hölzle, E., Goede, A. P. H., Visser, H., and Fricke, W.: SCIAMACHY - Scanning Imaging Absorption Spectrometer for Atmospheric Chartography, Acta Astronautica, 35(7), 445-451, 1995.

Chedin, A., Serrar, S., Scott, N. A., Crevoisier, C., and Armante, R.: First global measurement of midtropospheric $\mathrm{CO}_{2}$ from NOAA polar satellites: Tropical zone, J. Geophys. Res., 108(D18), 4581, doi:10.1029/2003JD003439, 2003.

Clerbaux, C., Hadji-Lazaro, J., Turquety, S., Megie, G., and Coheur, P.-F.: Trace gas measurements from infrared satellite for chemistry and climate applications, Atmos. Chem. Phys., 3, 14951508, 2003,

SRef-ID: 1680-7324/acp/2003-3-1495.

Coldewey-Egbers, M., Weber, M., Buchwitz, M., and Burrows, J. P.: Application of a modified DOAS method for total ozone retrieval from GOME data at high polar latitudes, Adv. Space Res., 34, 749-753, 2004.

Connor, B., Kuang, Z., Toon, G., Crisp, D., Wood, S., Barnet, C., and Buchwitz, M.: The averaging kernel of $\mathrm{CO}_{2}$ column measurements by the Orbiting Carbon Observatory (OCO), its use in inverse modeling, and comparison to AIRS, SCIAMACHY, and ground-based FTIR, Poster presented at the AGU Fall Meeting (available from http://www.iup.physik.uni-bremen. de/sciamachy/NIR_NADIR_WFM_DOAS/), 2003.

de Maziere, M., Barret, B., Blumenstock, T., et al.: Comparisons between SCIAMACHY scientific products and groundbased FTIR data for total columns of $\mathrm{CO}, \mathrm{CH}_{4}$, and $\mathrm{N}_{2} \mathrm{O}$, in: Proceedings of Second Workshop on the Atmospheric Chemistry Validation of ENVISAT (ACVE-2), ESA/ESRIN, Frascati, Italy, 3-7 May 2004, ESA SP-562 (on CD), 2004.

Frankenberg, C., Platt, U., and Wagner, T.: Iterative maximum a posteriori (IMAP-)DOAS for retrieval of strongly absorbing trace gases: Model studies for $\mathrm{CH}_{4}$ and $\mathrm{CO}_{2}$ retrieval from nearinfrared spectra of SCIAMACHY onboard ENVISAT, Atmos. Chem. Phys., 5, 9-22, 2005,

SRef-ID: 1680-7324/acp/2005-5-9.

Gloudemans, A. M. S., Schrijver, H., Straume, A. G., Aben, I., Maurellis, A. N., Buchwitz, M., de Beek, R., Frankenberg, C., Wagner, T., and Meirink, J. F.: $\mathrm{CH}_{4}$ and $\mathrm{CO}$ total columns from SCIAMACHY: Comparisons with TM3 and MOPITT, in: Pro- 
ceedings of Second Workshop on the Atmospheric Chemistry Validation of ENVISAT (ACVE-2), ESA/ESRIN, Frascati, Italy, 3-7 May 2004, ESA SP-562 (on CD), 2004.

Goody, R. M. and Yung, Y. L.: Atmospheric Radiation, Oxford University Press, New York, 1989.

Gurney, K. R., Law, R. M., Denning, A. S., Rayner, P. J., Baker, D., Bousquet, P., Bruhwiler, L., Chen, Y.-H., Ciais, P., Fan, S., Fung, I. Y., Gloor, M., Heimann, M., Higuchi, K., John, J., Maki, T., Maksyutov, S., Masarie, K., Peylin, P., Prather, M., Pak, B. C., Randerson, J., Sarmiento, J., Taguchi, S., Takahashi, T., and Yuen, C.-W.: Towards robust regional estimates of $\mathrm{CO}_{2}$ sources and sinks using atmospheric transport models, Nature, 415, 626-629, 2002.

Heimann, M. and Körner, S.: The Global Atmospheric Tracer Model TM3, Model Description and Users Manual Release 3.8a, Tech. Rep. 5, Max Planck Institute for Biogeochemistry (MPIBGC), Jena, Germany, 2003.

Houweling, S., Kaminski, T., Dentener, F., Lelieveld, J., and Heimann, M.: Inverse modeling of methane sources and sinks using the adjoint of a global transport model, J. Geophys. Res., 105(D21), 26 137-26 160, 1999.

Houweling, S., Breon, F.-M., Aben, I., Rödenbeck, C., Gloor, M., Heimann, M., and Ciais, P.: Inverse modeling of $\mathrm{CO}_{2}$ sources and sinks using satellite data: A synthetic inter-comparison of measurement techniques and their performance as a function of space and time, Atmos. Chem. Phys., 4, 523-538, 2003,

SRef-ID: 1680-7324/acp/2004-4-523.

Kleipool, Q.: SCIAMACHY: Recalculation of OPTEC5 NonLinearity, Tech. Rep. SRON-SCIA-PhE-RP-013, available from the author (Q.L.Kleipool@ sron.nl), SRON, Utrecht, The Netherlands, 2003.

Kobayashi, H., Shimota, A., Kondo, K., Okumura, E., Kameda, Y., Shimoda, H., and Ogawa, T.: Development and evaluation of the Interferometric Monitor for Greenhouse Gases: a high throughput Fourier transform infrared radiometer for nadir Earth observations, Appl. Opt., 38, 6801-6807, 1999a.

Kobayashi, H., Shimota, A., Yoshigahara, C., Yoshida, I., Uehara, Y., and Kondo, K.: Satellite-borne high-resolution FTIR for lower atmosphere sounding and its evaluation, IEEE Transactions on Geoscience and Remote Sensing, 37 (3), 1496-1507, 1999b.

Krol, M. C., Houweling, S., Bregman, B., van den Broek, M., Segers, A., van Velthoven, P., Peters, W., Dentener, F., and Bergamaschi, P.: The two-way nested global chemistry-transport zoom model TM5: Algorithm and applications, Atmos. Chem. Phys., 5, 417-432, 2005,

SRef-ID: 1680-7324/acp/2005-5-417.
Lelieveld, J. and Dentener, F. J.: What controls tropospheric ozone?, J. Geophys. Res., 105, 3531-3551, 2000.

Noël, S., Buchwitz, M., and Burrows, J. P.: First retrieval of global water vapour column amounts from SCIAMACHY measurements, Atmos. Chem. Phys., 4, 111-125, 2004,

SRef-ID: 1680-7324/acp/2004-4-111.

Olivier, J. G. J.: Greenhouse gas emissions: 1. Shares and trends in greenhouse gas emissions; 2. Sources and Methods; Greenhouse gas emissions for 1990 and 1995, in $\mathrm{CO}_{2}$ emissions from fuel combustion 1971-2000, ISBN 92-64-09794-5, pp. III.1-III.31, International Energy Agency (IEA), Paris, 2002 edn., 2002.

Press, W., Teukolsky, S., Vetterling, W., and Flannery, B.: Numerical Recipes in Fortran, Cambridge University Press, London, 1992.

Rayner, P. J. and O'Brian, D. M.: The utility of remotely sensed $\mathrm{CO}_{2}$ concentration data in surface inversions, Geophys. Res. Lett., 28, 175-178, 2001.

Rothman, L. S., Barbe, A., Benner, D. C., Brown, L. R., CamyPeyret, C., Carleer, M. R., Chance, K., Clerbaux, C., Dana, V., Devi, V. M., Fayt, A., Flaud, J. M., Gamache, R. R., Goldman, A., Jacquemart, D., Jucks, K. W., Lafferty, W. J., Mandin, J. Y., Massie, S. T., Nemtchinov, V., Newnham, D. A., Perrin, A., Rinsland, C. P., Schroeder, J., Smith, K. M., Smith, M. A. H., Tang, K., Toth, R. A., Vander Auwera, J., Varanasi, P., and Yoshino, K.: The HITRAN molecular spectroscopic database: edition of 2000 including updates through 2001, J. Quant. Spectrosc. Radiat. Transfer, 82, 5-44, 2003.

Takahashi, T., Sutherland, S. C., Sweeney, C., Poisson, A., Metzl, N., Tilbrook, B., Bates, N., Wanninkhof, R., Feely, R. A., Sabine, C., Olafsson, J., and Nojiri, Y.: Global sea-air $\mathrm{CO}_{2}$ flux based on climatological surface ocean $\mathrm{pCO}_{2}$, and seasonal biological and temperature effects, Deep-Sea Res., 49, 1601-1622, 2002.

Warneke, T., de Beek, R., Buchwitz, M., Notholt, J., Schulz, A., Velazco, V., and Schrems, O.: Shipborne solar absorption measurements of $\mathrm{CO}_{2}, \mathrm{CH}_{4}, \mathrm{~N}_{2} \mathrm{O}$ and $\mathrm{CO}$ and comparison with SCIAMACHY WFM-DOAS retrievals, Atmos. Chem. Phys. Discuss., 5, 847-862, 2005

SRef-ID: 1680-7375/acpd/2005-5-847.

Yang, Z. H., Toon, G. C., Margolis, J. S., and Wennberg, P. O.: Ground based inversion of $\mathrm{CO}_{2}$ column densities from solar spectra, Geophys. Res. Lett., 29, doi:10.1029/2001GL014537, 2002. 